\title{
Caspase-1 Activity in Microglia Stimulated by Pro-Inflammagen Nanocrystals
}

\author{
Alexandre Moquin, ${ }^{\dagger, \|}$ Eliza Hutter, ${ }^{\S, \|}$ Angela O. Choi, ${ }^{\S}$ Armen Khatchadourian, ${ }^{\S}$ Annie Castonguay, ${ }^{\S}$ \\ Françoise M. Winnik, ${ }^{t, \pm, \perp}$ and Dusica Maysinger ${ }^{\S, *}$
}

\begin{abstract}
${ }^{\dagger}$ Faculty of Pharmacy and ${ }^{\ddagger}$ Department of Chemistry, Université de Montréal, CP 6128 Succursale Centre Ville, Montreal, Quebec H3C 3J7, Canada, ${ }^{\S}$ Department of Pharmacology and Therapeutics, McGill University, 3655 Promenade Sir-William-Osler, Room 1314, McIntyre Medical Sciences Building, Montreal, Quebec H3G 1Y6, Canada., and ${ }^{\perp}$ WPI International Center for Materials Nanoarchitectonics (MANA) (satellite laboratory), National Institute for Materials Science, 1-1 Namiki, Tsukuba, Ibaraki 305-0044 Japan. "These authors share equal first authorship.
\end{abstract}

\begin{abstract}
Although caspase- 1 is a key participant in inflammation, there is no sensitive assay to measure its enzymatic activity in real time in cells or animals. Here we describe a nanosensor for caspase-1 ratiometric measurements, consisting of a rhodamine-labeled, caspase- 1 cleavable peptide linked to quantum dots (QDs). Microglia cells were stimulated by lipopolysaccharide (LPS) and by hybrid nanoparticles LPS-QDS. These stimuli activated caspase-1 in microglia monolayers and in the mouse brain, while a selected caspase inhibitor markedly reduced it. LPS-QDs entered into the lysosomal compartment and led to an enlargement of these cellular organelles in the exposed
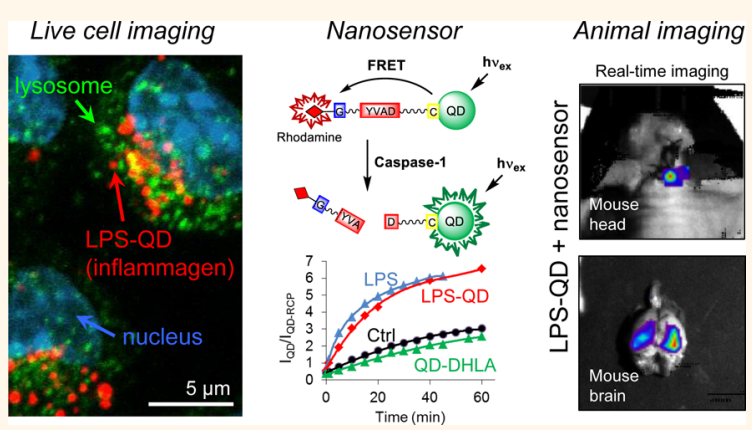

microglia. Both lysosomal swelling and mitochondrial impairment contributed to caspase- 1 activation and to the consequent interleukin-1 $\beta$ release. The results from these studies highlight how the unique properties of QDs can be used to create versatile biotools in the study of inflammation in real time in vivo.
\end{abstract}

KEYWORDS: nanosensor · caspase-1 $\cdot$ lipopolysaccharide $\cdot$ quantum dots · asymmetrical flow field-flow fractionation · microglia $\cdot$ inflammation

\begin{abstract}
$\Lambda$ $\mathrm{n}$ acute inflammatory response to an insult is largely a protective cellular response. An unopposed acute inflammatory process persists, leading to the characteristic chronic inflammation. Commonly, the sequel would be a deterioration of physiological function. An early intervention is therefore important to reduce or eliminate this undesirable consequence. To this end, several biomarkers of inflammation have been measured and tested; these biomarkers are mainly the products of enzymatic reactions. Caspase- 1 is one of the most prominent of the enzymes involved in inflammation. ${ }^{1}$

Inflammation can be induced by numerous exogenous agents, including airborne particles, biological aggregates, nanocrystals (quantum dots (QDs)) and lipopolysaccharides (LPS). ${ }^{2}$ These inflammagens are recognized by macrophages and microglia and some of them bind to cell surface
\end{abstract}

receptors such as Toll-like receptors (TLR). In particular, endotoxins, including LPS, bind TLR-4 and trigger receptor dimerization at the plasma membrane, which, in turn, activate signal transduction cascades to induce inflammation. ${ }^{1}$ TLR-4 activation initiates both genomic and nongenomic inflammatory responses (i) by activating the transcription factor NF- $\kappa$ B, which translocates to the nucleus and induces the expression of pro-inflammatory cytokines (e.g., pro-interleukins), and (ii) by internalizing the bound endotoxin stimuli, fusing with lysosomes and triggering the formation of inflammasomes (Figure 1A). Nod-like receptor protein-3 (NLRP-3) inflammasome $\mathrm{e}^{3-6}$ is one of the most wellstudied inflammasomes and contains the precursor pro-caspase-1, which is cleaved following inflammatory stimuli and releases its active form, caspase-1. ${ }^{7}$ Caspase- 1

is a cysteine protease which converts @2013 American Chemical Society
* Address correspondence to dusica.maysinger@mcgill.ca.

Received for review January 14, 2013 and accepted October 9, 2013.

Published online October 09, 2013 $10.1021 / \mathrm{nn} 404473 \mathrm{~g}$ 


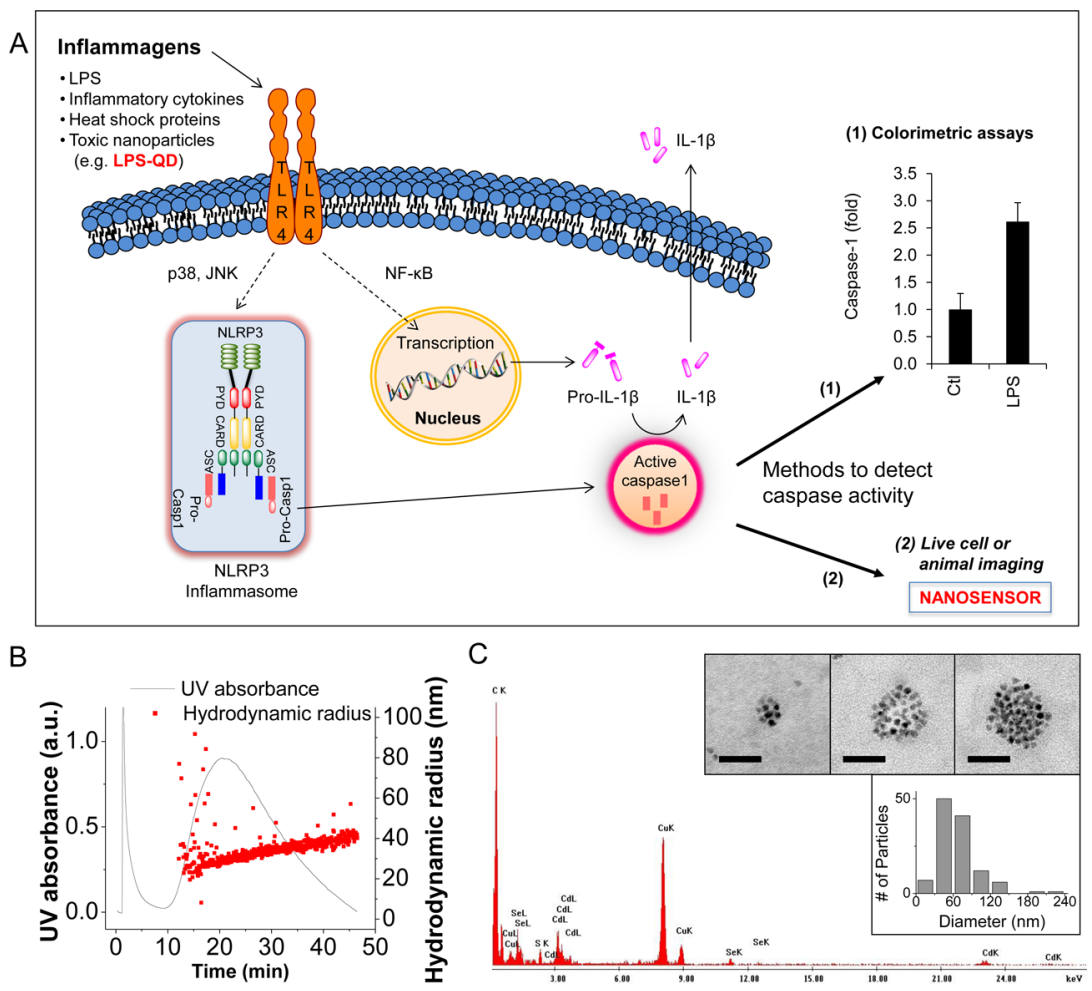

Figure 1. Caspase-1 activation by inflammagenic nanoparticles. (A) Mechanisms of caspase-1 activation in response to inflammatory stimuli. Inflammagens, including LPS-QDs, induce the activation of Toll-like receptor-4 (TLR-4) followed by activation of NLRP3 inflammasome via p38 and JNK signaling. Active caspase-1 will be released (cleaved from the pro-caspase 1 in the inflammasomes) and will cleave pro-IL-1 $\beta$, leading to the ultimate release of the mature form of the pro-inflammatory cytokine (IL-1 $\beta$ ). NF- $\kappa$ B signaling is also triggered by TLR4 receptor activation, resulting in the increased expression of inflammatory genes including pro-IL-1 $\beta$. In addition to traditional colorimetric assays to measure enzymatic activity enzymes in cell lysates, we propose a nanosensor to measure caspase- 1 activity in live cells and in animals. (B) Size determination by AF4 (asymmetrical flow field-flow fractionation)/UV/DLS of lipopolysaccharide-quantum dots (LPS-QD) run in a solution of $\mathrm{NaCl}(20 \mathrm{mM})$ on a $10 \mathrm{kDa}$ regenerated cellulose membrane. The fractogram shows the absorbance signal at $280 \mathrm{~nm}$ plotted versus time of elution and the hydrodynamic radii in red. (C) Elemental analysis by energy dispersive X-ray spectroscopy (EDS). (Top inset) Transmission electron microscopy (TEM) images of LPS-QD nanoparticles. Images were taken by the Tecnai $120 \mathrm{kV}$ electron microscope using a CCD camera. Scale bars represent $50 \mathrm{~nm}$. (Bottom inset) Histogram shows the size distribution of LPS-QD nanoparticles as deposited and dried on Formvar-coated TEM grids $(n=120)$. Sizes were measured using the ImageJ software. EDS spectrogram was obtained on a Philips CM200 200 kV TEM with a Gatan Ultrascan $10002 k \times 2 k$ CCD Camera System Model 895 and EDAX Genesis EDS.

pro-interleukin-1 $\beta$ (Pro-IL-1 $\beta$ ) to the active cytokine IL$1 \beta$, which is then released extracellularly to propagate inflammatory signals.

Lipopolysaccharides (LPS), commonly used as inducers of inflammation, are amphiphilic molecules found in the membranes of Gram-negative bacteria and are responsible for the endotoxicity of the bacteria. In nonsterile locations, LPS are ubiquitous, constituting widespread contaminants which can easily get into contact with different nanomaterials. ${ }^{8-10}$ LPS is composed of three parts, the most conserved of which, known as lipid $A^{11}$ is a lipophilic group composed of alkyl chains localized inside the bacterial membrane. LPS is responsible for the endotoxicity of Gramnegative bacteria (e.g., in septic shock). The central part of LPS is a core polysaccharide composed of carboxylated sugar moieties, and it exhibits a net negative charge at physiological $\mathrm{pH}$. In the presence of divalent cations $\left(\mathrm{Ca}^{2+}\right.$ and $\left.\mathrm{Mg}^{2+}\right)$, the electrostatic interactions between the phosphates in lipid $\mathrm{A}$ and the adjacent keto-deoxyoctulosonate (Kdo) moieties play a role in the high stability of the LPS molecules in the bacterial membrane. The third part of LPS is the O-antigen group, a polysaccharide-rich chain with strain specific composition. This contributes to the variability of the overall LPS-induced biological activity, and therefore, it is of relevance when performing biological experiments to indicate the bacterial strain from which LPS originates (e.g., Escherichia coli 0111:B4).

Particulate and other environmental inflammagens including nanocrystals can access the central nervous system (CNS) in particular by way of the olfactory mucosa and the associated nerves that bypass the blood brain barrier. ${ }^{12}$ Microglia cells, the brain cells which first sense this danger, are also able to defend the brain from it. ${ }^{13}$ Under physiological conditions, the main function of these neural cells is to provide protective patrolling of the brain; however, in the presence of endotoxins such as LPS, they adopt the characteristics of brain macrophages in which 
caspase- 1 activity becomes increased. The present studies are focused on microglia, as these are biological "sensors" that avidly respond to pro-inflammatory stimuli.

The standard caspase- 1 activity assays (Western blots, colorimetric assays) are not suitable for use in living cells and their sensitivities are not high enough to detect subtle changes in the enzyme activity. The best available assays to date are the fluorometric ones, but even these are limited in sensitivity because they use organic fluorophores and are based on fluorescence intensity changes rather than fluorescence lifetimes or peak ratios. Our approach is based on the principle of fluorescence energy transfer (FRET) between QDs (donors) and a fluorophore (acceptor). ${ }^{14-17}$ We anticipated that this construct has several advantages over the commercially available ones. First, the use of QDs rather than organic fluorophores ensures a high quantum yield, a broad excitation spectrum and spectral tunability. Several laboratories have exploited the unique properties of nanostructured materials, including quantum dots (QDs), to develop tools to measure changes in biomarkers of different pathologies. ${ }^{18-20}$ QDs are highly luminescent nanocrystals with numerous possible surface modifications and emissions from blue to infrared spectral regions. QDs are stable, and the new preparations have improved in terms of cytotoxicity. However, there are still limitations to overcome. ${ }^{21-23}$ QD luminescence allows for the study of the biodistribution of labeled entities and also for the indirect quantification of the uptake of molecules of interest. ${ }^{24-28}$

Multiple acceptors can be conjugated to one QD particle, thus decreasing the amount of sensor necessary for measurement. Ratiometric measurements are concentration independent and more sensitive than those based on fluorescence intensity changes. In our construct, $\mathrm{CdSe}(\mathrm{CdZnS})$ quantum dots were functionalized by a fluorescently labeled short peptide containing the preferential substrate for the caspase-1, YVAD. ${ }^{17,29}$ Upon excitation, the transfer of QD energy to the dye (rhodamine-B) takes place, resulting in an emission observed at the wavelength specific for the dye. After enzymatic cleavage of the peptide molecules, the rhodamine-B (acceptor) molecules are liberated and diffuse away from the QDs. FRET cannot take place any more; hence, direct emission from the QDs takes place exclusively. Monitoring the ratio of the intensity of QD emission to that of rhodamine emission over time provides information on the rate of the caspase-1 enzyme induced substrate conversion.

Some similar constructs have been described for several proteases, ${ }^{15,17,30-34}$ one of them being a caspase- 1 sensor developed by Medintz et al. ${ }^{14}$ based on the FRET principle which occurs between selected QDs and organic fluorophores. We have selected rhodamine as the organic fluorophore and have synthesized the QDs according to the maximum absorbance wavelengths of rhodamine. To our knowledge, the present report is the first to describe their use in the monitoring of caspase-1 activity in microglial cells and in live animals.

\section{RESULTS AND DISCUSSION}

The results from these studies show the physicochemical properties of modified QDs which can be used for the development of useful biological tools for multiple purposes including stimulation of neural cells and measurements of enzymatic activity in activated microglia.

Different "danger" stimuli, from endogenous or exogenous stressors, (e.g., misfolded oligomerized proteins, bacterial toxins or bacteria themselves) can induce inflammatory processes including formation and activation of inflammasomes. Inflammasome activators often cause formation of mitochondria-derived reactive oxygen species $(\mathrm{ROS})^{35}$ and lysosomal destabilization. ${ }^{36,37}$ Several laboratories, including ours, have shown that QDs can induce excessive ROS formation ${ }^{38-41}$ and activation of microglia, ${ }^{42}$ and the release of cytokines including interleukin- $1 \beta$ (IL$1 \beta){ }^{43,44}$ However, these earlier studies did not provide experimental evidence for a mechanistic link between the activation of microglia, lysosomal status, and activation pattern of caspase- 1 together with the subsequent release of IL- $1 \beta$. In the current study, we describe a ratiometric QD-based nanosensor for caspase-1 activity detection.

We opted to generate a sensor for caspase- 1 and then to take it one step further by using it both in vitro and in vivo. We first investigated the microglia responses to LPS and established the properties of lipopolysaccharide (LPS)-modified QDs as inflammasome activators. Our main purpose of using QDs was to exploit their unique photophysical properties as integral parts of a caspase- 1 sensor. We also established the key steps in signal transduction initiated at the plasma membrane from TLR-4 receptors, functional changes in the organelles (mitochondria and lysosomes) and caspase- 1 activity. The results from the in vitro and whole animal studies establish a proof of principle for the effectiveness of the QD-based caspase-1 sensor to measure enzymatic activity in the inflamed periphery and the central nervous system.

Inflammagens and Their Effects on Microglia. To establish a robust and reproducible model system for caspase-1 activation necessary for testing the nanosensor, we used microglia as model cells for the experiments in vitro. These cells are very sensitive to various insults and they are first to respond to them by changing their phenotype from surveyors to macrophage-like cells. ${ }^{45-47}$ This functional change is accompanied by morphological transformation from ramified to more 


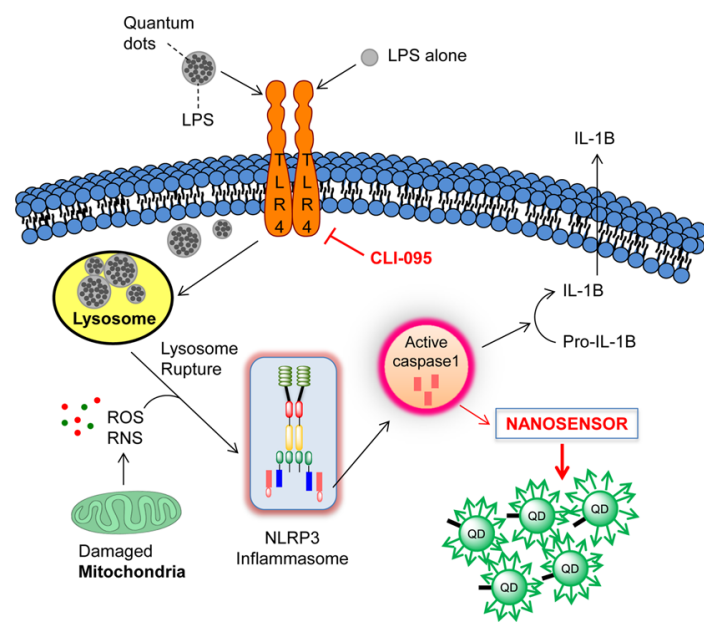

Scheme 1. Proposed mechanism of Caspase-1 activation by autoassembled LPS-QD nanoparticles. LPS-QD nanoparticles lead to the activation of Toll-like receptor-4 (TLR-4). The uptake of large nanoassemblies leads to lysosomal rupture followed by release of cathepsin B into the cytosol and NLRP3 inflammasome activation. Mitochondrial ROS leads to the transcriptional induction of pro-IL-1 $\beta$ and NLRP3 mediating inflammasome activation. Active caspase-1 will be released and will cleave pro-IL-1 $\beta$, leading to the ultimate release of the mature form of the proinflammatory cytokine (IL-1 $\beta$ ). ROS: reactive oxygen species. RNS: reactive nitrogen species.

amoeboid shape and production of biochemical markers of inflammation such as cytokines. ${ }^{48}$ Interleukins (e.g., IL-1 and IL-6) are found in inflamed tissues and secreted by activated microglia exposed to inflammagens. $\mathrm{IL}-1 \beta$ is a direct cleaving product of active caspase-1. Pro-IL-1 $\beta$ expression is initiated by TLR-4 activation; both genomic and nongenomic pathways are involved in the inflammatory processes of microglia (Scheme 1). ${ }^{49}$ Once IL- $1 \beta$ is produced and released from the cells, it binds to IL-1 receptors to trigger further inflammatory processes (Figure 1A). ${ }^{49}$

We first optimized experimental conditions for microglia activation with LPS, a well-established inflammagen in vitro and in vivo. We also employed hybrid nanoparticles LPS-QD nanoparticles as an additional control for activation of caspase- 1 in microglia. These LPS-QDs containing CdSe/ZnS ( $2 r=$ $5.3 \mathrm{~nm}$ ) had comparable pyrogenicity with LPS without nanocrystals (100 ng/mL both, based on LPS concentration); they were photoluminescent (emission at $615 \mathrm{~nm}$ ) and readily dispersed in aqueous media. Asymmetrical flow field-flow fractionation (AF4) analysis of LPS-QD suspension indicated that they contain nanoparticles of broad size distribution ranging from 50 to about $110 \mathrm{~nm}$ in hydrodynamic diameter (Figure 1A,B). Cryo-TEM (transmission electron microscopy) images of LPS-QD featured small dense dots distributed inside the spherical LPS structures, attributed to isolated or clustered QDs dispersed within the hydrophobic LPS core. Measurements of mitochondrial metabolic activity (Figure 2A) clearly show that there is a significant decrease (values were normalized for cell number) in the microglia exposed to LPS, LPS-QDs and antimycin A (a drug control for the reduction of mitochondrial metabolic activity).

Taking advantage of LPS-QD fluorescence and the ability to image them intracellularly, we set out to see if the relatively large size of the LPS-QD nanostructures prevented the internalization of LPS-QDs, a process which involves the toll-like receptor 4 (TLR-4), known to be essential for binding and activation of this receptor by LPS. ${ }^{7}$ The internalization of the LPS-QD nanoparticles in N9 microglia was monitored by two complementary methods: confocal microscopy and multiwell plate reader with fluorescence detection. Confocal micrographs (Figure 2C) revealed large fluorescent clusters inside the cells, which could be due to phagocytosis of these large structures. Semiquantitative spectrofluorometry confirmed that LPS-QDs were indeed internalized by microglia, but at a relatively slow rate. Since the internalization of LPS is dependent on binding with TLR-4 receptors, we speculated that LPS-QD internalization could also involve TLR-4. A pharmacological TLR-4 receptor blocker, CLI-095 was used, and pretreatment with the inhibitor significantly, but not completely, reduced the uptake of LPS-QDs (Figure 2E), suggesting additional mechanisms of internalization. Nanoparticle uptake into the cells can be via a combination of mechanisms mainly depending on the size of the nanoparticles. Some of these mechanisms include clathrin-dependent endocytosis, macropinocytosis and phagocytosis. ${ }^{50-52}$ Pharmacological inhibition of mitogen activated protein kinase p38 activation reduced the internalization of LPS-QDs suggesting that this mode of internalization could have been also involved (unpublished observation). It has been reported that in biological media with high salt content and different proteins, phagocytosis is an internalization mode complementary to other internalization modes in microglia. ${ }^{53-55}$ LPS and LPS-QD treatments also led to a significant increase of nitric oxide (NO), a product of the induction of nitric oxide synthase (Figure 2B). Inhibition of TLR-4 reduced the level of NO released to basal levels, suggesting that LPS-QDs also stimulate the genomic inflammatory responses in microglia.

We next investigated the effect of LPS and LPS-QDs on two other organelles, lipid bodies (LBs) and lysosomes. The rationale for investigating LBs was sparked by increasing evidence for this organelle to be markedly enhanced in size and number under inflammatory and stressful conditions. ${ }^{42,56,57}$ LBs have been proposed as dynamic organelles which can serve as "the temporary refugee camp" for proteins to protect them from hydrolytic cleavage. LPS-QDs did not associate with these organelles as revealed by the absence the fluorescent signal (yellow) indicative of LB (green, BODIPY 495/503) co-localized with LPS-QD 

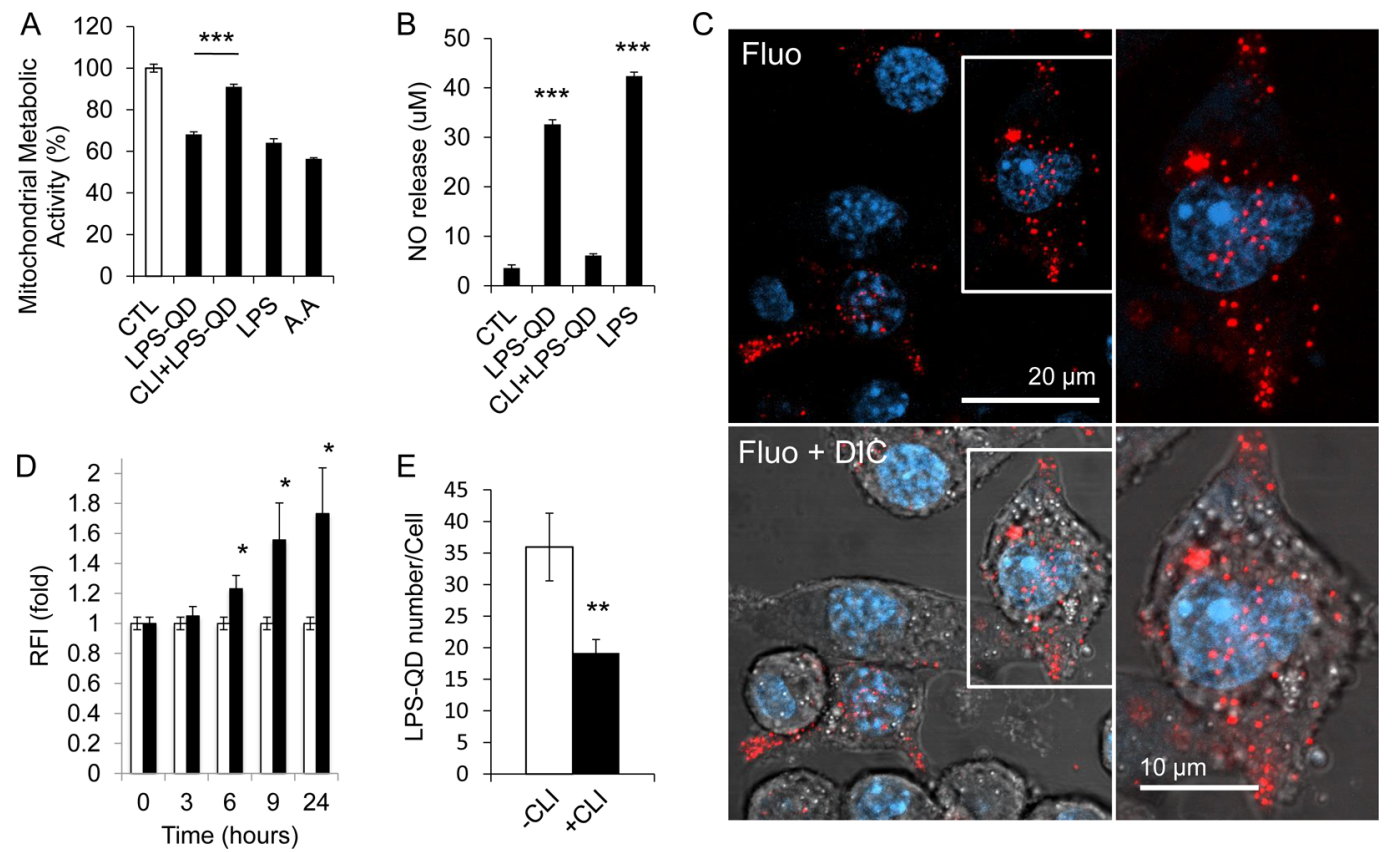

Figure 2. LPS-QDs induce inflammatory effects and are taken up in microglia. (A) Mitochondrial metabolic activity was assessed using the MTT reduction assay. Microglia were left untreated (white bar, 0 time), treated with LPS-QD $(10 \mu \mathrm{g} / \mathrm{mL}$, $24 \mathrm{~h})$, LPS (10 $\mu \mathrm{g} / \mathrm{mL}, 24 \mathrm{~h}$ ) or CLI-095 (CLI), a pharmacological TLR-4 receptor blocker ( $250 \mathrm{nM}, 30 \mathrm{~min}$ ), then exposed to LPS-QD nanoparticles $(10 \mu \mathrm{g} / \mathrm{mL}, 24 \mathrm{~h})$. Percentages of metabolic activity in treated cells were expressed relative to controls (untreated cells, set to $100 \%, n=9$ ). Antimycin A (A.A, $1 \mu \mathrm{M}, 24 \mathrm{~h}$ ) was used as a negative control for MTT assay. (B) Nitric oxide (NO) released from cells was measured after $24 \mathrm{~h}$ from treatments as described previously. (C) Confocal images (Z-stack) of intracellular LPS-QD (red) in microglia. Cells were treated with LPS-QD $(10 \mu \mathrm{g} / \mathrm{mL}$, based on LPS) for $24 \mathrm{~h}$ (in serum-free media). The extent of internalization of the LPS - QD was determined spectrofluorometrically to be $11.61 \pm 1.05 \%$ of the initial dose after $24 \mathrm{~h}$ of incubation $(n=3)$. Nuclei (blue) were labeled with Hoechst $33342(10 \mu \mathrm{M}, 10 \mathrm{~min})$. Fluorescence (Fluo) and differential interference contrast (DIC) images were used. Confocal Z-stack images consist of $10 \mathrm{Z}$-slices acquired at $0.4 \mu \mathrm{m}$ intervals. Scale bar: $20 \mu \mathrm{m}$. (Inset: right) Zoom-in to a single-cell. Scale bar: $10 \mu \mathrm{m}$. The white dots indicate lipid bodies. (D) Time-dependent uptake of LPS-QD. Microglia were left untreated (white bar, 0 time) or treated with LPS-QD $(10 \mu \mathrm{g} / \mathrm{mL})$ for $3,6,9$, and $24 \mathrm{~h}$. Mean fluorescence intensities were measured using image analysis software (Image J) and relative fluorescent intensities (RFI) were expressed as fold change with respect to untreated cells that were set to 1 . Statistically significant differences are indicated by ${ }^{*} p<0.05$ when compared to the untreated controls at each respective time point. (E) Effect of CLI095 (CLI), a pharmacological TLR-4 receptor blocker on the cellular uptake of LPS-QD nanoparticles. Cells were pretreated with CLI-095 (250 nM, $30 \mathrm{~min}$ ) then exposed to LPS-QD nanoparticles $(10 \mu \mathrm{g} / \mathrm{mL}, 24 \mathrm{~h})$. Data obtained from fluorescent images shows the average number of LPS-QD per cell $(n=24)$, quantified using ImageJ software. The data are expressed as mean \pm SEM obtained from at least three independent experiments performed in triplicates. Statistically significant differences are indicated by ${ }^{*} p<0.05,{ }^{* *} p<0.01$, and ${ }^{* *} p<0.001$.

(red) (Figure 3A). LPS-QD nanoparticles were also absent from the nucleus labeled with Hoechst 33342. Lipid bodies were easily detectable in cells treated with LPS or LPS-QD, but there was no association between the QDs and LBs under any of the tested conditions (e.g., different LPS concentrations from $10 \mathrm{ng} / \mathrm{mL}$ to $10 \mu \mathrm{g} / \mathrm{mL}$ and for different lengths of times of the exposure from $15 \mathrm{~min}$ to $24 \mathrm{~h}$ ). These findings suggest that the increased sizes of LBs in activated microglia by LPS and LPS-QDs most likely resulted from the fusion of small $\mathrm{LBs}^{56}$ rather than the incorporation of QDs and consequential size enhancement.

In contrast to the absence of co-localization of LPS-QDs with LBs, there was a significant co-localization with lysosomes (Figure 3B). Three-dimensional reconstruction from the $z$-stacks revealed overlapping fluorescence signals ( $14.5 \% \pm 2.9 \%, p<0.05$, yellow) originating from LPS-QDs (red) and LAMP1-immunopositive lysosomes (green). The assessment of lysosomal sizes by $3 \mathrm{D}$ reconstruction analysis shows that the size of lysosomes in LPS-QD nanoparticle-treated cells is markedly increased ( $1.5 \pm 0.35$ fold, $p<0.05$, Figure $3 C$ ) and they are possibly leaky because many QDs were found outside of lysosomes. Indeed the experiments with acridine orange confirmed the leaky lysosomes as the control (untreated cells) revealed both orange and green fluorescence, whereas the LPS and LPS-QD-treated cells were predominantly emitting the fluorescence in the green spectral region (data not shown). This shift from orange to green has been exploited in biology for studies addressing the questions of lysosomal stability. ${ }^{58}$

At physiological $\mathrm{pH}$ the phosphate and carboxylate groups present in the lipid-A part of LPS confer on the LPS-QD nanoparticles a net negative surface charge $(\zeta=-12.0 \pm 1.2 \mathrm{mV})$. Neutralisation of the carboxylate groups in acidic $\mathrm{pH}$ enhances the hydrophobicity of the LPS-QDs interface and triggers their agglomeration. This was confirmed by AF4 analysis of LPS-QD suspensions brought to lysosomal pH (5.0) (Figure 3D). 

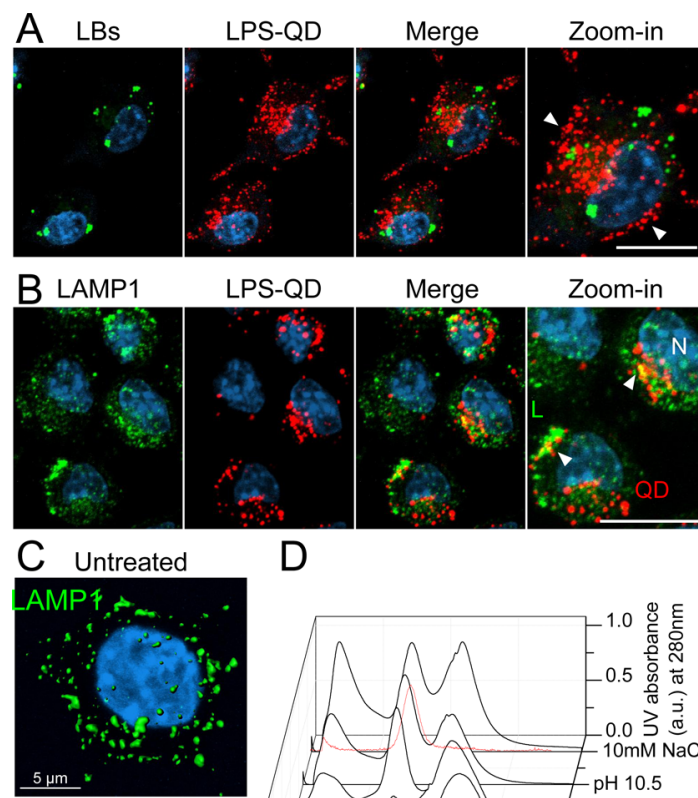

LPS-QD
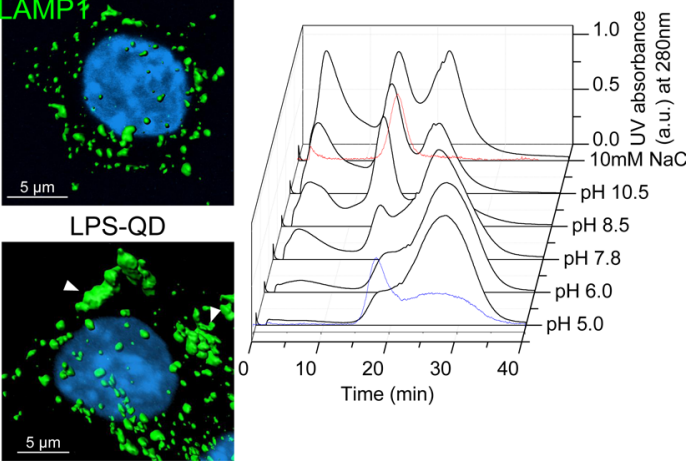

Figure 3. Cellular localization of LPS-QD in microglia. Cells were treated with LPS-QD $(10 \mu \mathrm{g} / \mathrm{mL})$ for $24 \mathrm{~h}$ (in serumfree media). (A) Confocal Z-stack images showing LPS-QD (red) and lipid bodies (green). Note that LPS-QDs are found in close proximity with the plasma membrane (arrowheads, right panel). Lipid bodies (LBs) were labeled with HCS LipidTOX for $30 \mathrm{~min}$ and nuclei (blue) were labeled with Hoechst 33342 (10 $\mu \mathrm{M}, 10 \mathrm{~min}$ ). Z-stack images consist of 15 Z-slices acquired at $0.4 \mu \mathrm{m}$ intervals. Scale bar: $10 \mu \mathrm{m}$. (B) Confocal image (Z-stack) of LPS-QD and LAMP-1 (green). LAMP-1 was detected by using a primary antibody (rabbit) to LAMP-1, followed by a secondary antibody (anti-rabbit) conjugated to Alexa Fluor 488. Yellow spots in the merged images suggest that LPS-QD co-localize with LAMP-1 (arrowheads in right panel). $L=$ lysosomes, $Q D=L P S-Q D$, $N=$ nucleus. Scale bar: $10 \mu \mathrm{m}$. (C) 3D-reconstruction of LAMP-1 in LPS-QD treated cells. Lysosomes look aggregated (arrowheads) in cells treated with LPS-QD. (D) AF4 fractograms of unpurified LPS-QD solution containing traces of free-LPS, QD-associated LPS and large LPS agglomerates at different $\mathrm{pH}$. The red line corresponds to the luminescence signal $\left(\lambda_{\text {ex. }} 365 \mathrm{~nm}, \lambda_{\text {em. }} 615 \mathrm{~nm}\right)$ of the LPS-QD in sodium chloride $(10 \mathrm{mM})$ conditions, and the blue line corresponds to the luminescence signal $\left(\lambda_{\text {ex. }}\right.$. $365 \mathrm{~nm}, \lambda_{\mathrm{em}} 615 \mathrm{~nm}$ ) obtained during the elution of the LPS-QD in $\mathrm{pH}$ 5.0. The running buffer was $1 \mathrm{mM}$ phosphate salts at $\mathrm{pH} 7.4$ using a regenerated cellulose membrane with a $10 \mathrm{kDa}$ cutoff.

The fractogram featured the major band at elution times significantly longer than those that are characteristic of LPS-QD suspensions in neutral $\mathrm{pH}$ (Figure 3D), suggesting the formation of large agglomerates, reaching diameters of up to $1-2 \mu \mathrm{m}$.

The evidence of significant swelling and agglomeration of the LPS-QD nanoparticles in low $\mathrm{pH}$ provides an explanation to how the LPS-QD may escape the lysosomal compartments. The considerable increase in sizes could cause the bursting of the lysosomal compartments, a release of their contents and activation of inflammasomes. Lysosomal instability in microglia exposed to the selected inflammagens in this study was revealed by leakage of acridine orange and in other studies by measurements of cathepsins. ${ }^{58,59}$

In summary, our results from AF4 measurements indicate that at low $\mathrm{pH}$, comparable to that in lysosomes ( $\mathrm{pH} 4.5-5$ ), LPS-QD form agglomerates. Agglomeration of different biological and artificial materials within lysosomes commonly leads to an increase in lysosomal size and eventually to their destabilization, ${ }^{58-60}$ along with the activation of caspase-1 via the activation of inflammasomes.

Caspase-1 Activation by Inflammagens and Measurements of the Enzyme Activity in Vitro and in Vivo. It is well documented that LPS-activation of microglia leads to the formation of NOD like receptor (NLRP) inflammasomes. ${ }^{3}$ When activated, these protein complexes recruit procaspase-1, which is then converted to its free, "active" caspase- 1 form. The main task of the active enzyme is the conversion of pro-IL- $1 \beta$ into its mature form, IL$1 \beta .^{3,61}$ In LPS and LPS-QD treated microglia, we found significantly increased levels of IL-1 $\beta$ as determined by ELISA assays (Figure $4 \mathrm{~A}){ }^{43}$ The viability of the cells exposed to LPS and/or LPS-QD (100 $\mathrm{ng} / \mathrm{mL}$ and $10 \mu \mathrm{g} / \mathrm{mL}$ ) in the presence of serum was within $10 \%$ from the control. To determine the activity of caspase- 1 which leads to the conversion of pro-IL- $1 \beta$ to IL- $1 \beta$, we developed and employed a novel nanosensor. This caspase-1 nanosensor is composed of QDs and rhodamine-B molecules, connected through a short peptide, cleavable by caspase- 1 (Figure 4B). The principle of the assay is the ratiometric measurement of QD luminescence and rhodamine fluorescence. The composition, size, and the emission of QDs used to construct the caspase- 1 sensor were the following: $\mathrm{CdSe}(\mathrm{CdZnS}), d=$ $2.7 \mathrm{~nm}, \lambda_{\text {em }}=551 \mathrm{~nm} .^{62}$ These QDs were modified by the fluorescently labeled short peptide, rhodamineGRYVADYDDDDLDPATC (RCP, $\lambda_{\mathrm{ex}}=561 \mathrm{~nm}, \lambda_{\mathrm{em}}=$ $582 \mathrm{~nm}$ ) (Figure S1). The thiol group of the first amino acid cysteine was used to bind the peptide to the QD surfaces. The sequence of RCP contained caspase- 1 cleavable sequence YVAD. ${ }^{14,17,29}$ When the QDs are excited $\left(\lambda_{\mathrm{ex}}=355 \mathrm{~nm}\right)$, they transfer their energy to the dye molecules (rhodamine) and the emission is observed at the wavelength specific for the dye $(590 \mathrm{~nm})$ (Figure 4C). After enzymatic cleavage of the peptide molecules, the acceptor molecules are detached from the QDs, they no longer provide an efficient energy transfer channel to them, and the emission spectra changes back to that of QDs (551 nm).

Monitoring the ratio between the emission peaks of QDs and fluorophores ( $\left.I_{\mathrm{QD}} / l_{\mathrm{QD}-\mathrm{RCP}}\right)$ provides information on the rate of the substrate cleavage indicative of enzyme activity (Figure 5A). To assess the effectiveness of caspase-1 sensor in biological samples, we first 
A

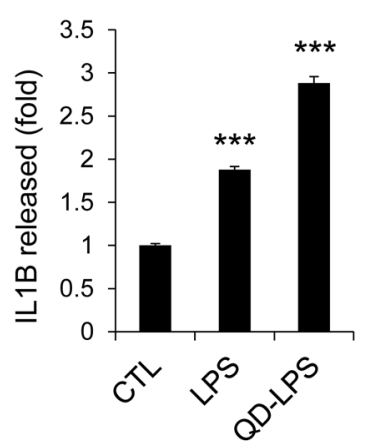

B

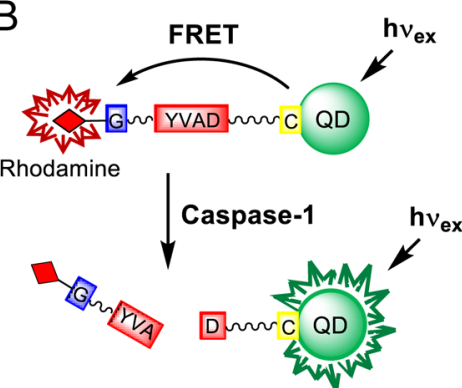

C

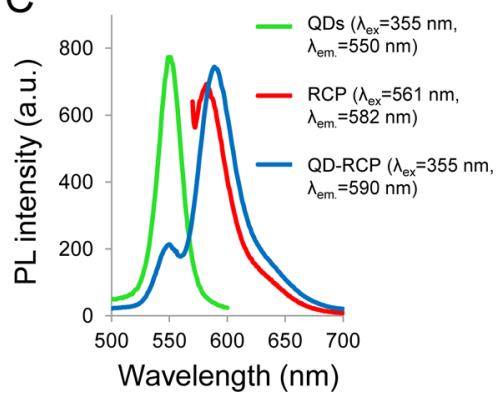

Figure 4 . The principle of caspase-1 nanosensor measurement and Interleukin-1 $\beta$ (IL-1 $\beta$ ) release. (A) IL-1 $\beta$ cytokines released from microglia cells exposed to LPS $(10 \mu \mathrm{g} / \mathrm{mL}$, $24 \mathrm{~h})$ or LPS-QD (10 $\mu \mathrm{g} / \mathrm{mL}, 24 \mathrm{~h})$ were measured using respective ELISA kit and expressed relative to controls (untreated cells, set to $1, n=9$ ). ${ }^{* *} p<0.001$. Cytotoxicity and cell number were assessed by trypan blue assay. There was no significant difference in the cell number loss between LPS and LPS-QD treated cells. However, there was a significant difference between the untreated and treated cells. (B) Schematic showing the principle of the sensor. The caspase-1 nanosensor is composed of QDs and rhodamineB molecules, connected through a short peptide, cleavable by caspase-1. When the QDs are excited, they transfer their energy to the dye molecules and the emission is observed at the wavelength specific for the dye (FRET: Fluorescence Resonance Energy Transfer). After enzymatic cleavage of the peptide molecules, the acceptor molecules are detached from the QDs, they no longer provide an efficient energy transfer channel to them, and the emission spectra changes back to that of QDs. (C) Emission spectra of the QDs, rhodamine-conjugated peptide (RCP) and the QD-RCP construct (FRET).

treated microglia cells with LPS or with nanocrystals modified with LPS or with nanocrystals, decorated with dihydrolipoic acid (DHLA, as a negative control for caspase-1 activation). It was anticipated that only LPS or LPS-functionalized nanocrystals would activate caspase-1, whereas DHLA-modified nanocrystals would

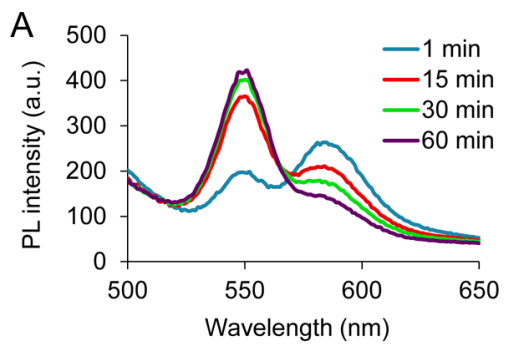

B
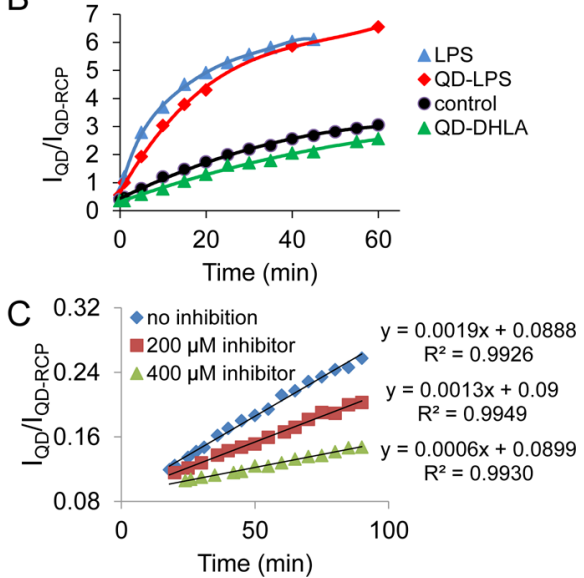

Figure 5. Measurements of caspase-1 activity in vitro using the nanosensor. (A) Representative fluorescence spectra of the nanosensor in the presence of LPS treated cell lysates at several time points. The ratio of the two peaks (550 and $582 \mathrm{~nm}$ ) changes rapidly during the first hour. (B) Change of ratio of fluorescence intensity at $550 \mathrm{~nm}\left(I_{\mathrm{QD}}\right)$ and $582 \mathrm{~nm}$ $\left(I_{\text {QDRCP }}\right)$ during the first $60 \mathrm{~min}$ in LPS $(100 \mathrm{ng} / \mathrm{mL})$, LPS $-Q D$ (100 ng/mL), QD-DHLA $(0.31 \mathrm{nM})$ treated and control (untreated) cell lysates $\left(5 \times 10^{5}\right.$ cells). (C) Change of ratio of fluorescence intensity at $550 \mathrm{~nm}\left(I_{\mathrm{QD}}\right)$ and $582 \mathrm{~nm}$ $\left(I_{\mathrm{OD}-\mathrm{RCP}}\right)$ during the first $90 \mathrm{~min}$ in untreated cell lysates $\left(1.25 \times 10^{5}\right.$ cells) without the enzyme inhibitor present and in the presence of 200 and $400 \mu \mathrm{M}$ caspase-1 specific inhibitor, Z-WEHD-FMK.

not. The release of inflammatory mediators, nitric oxide and IL-1 $\beta$, was not significantly different from the control in microglia treated with QD-DHLA (Figure S2), and our previous study also showed that other QDs induce a transient inflammatory response in microglia. ${ }^{42}$ Cell lysates collected after exposure to these treatments were used for measurements of caspase- 1 enzymatic activity using our nanosensor. The basal caspase- 1 activity was determined in the absence of inflammagen (untreated) microglia. The results of the peak ratio changes, in lysates obtained from microglia (N9) treated with LPS, LPS-QDs, QD-DHLA, or from untreated cells, are shown (Figure $5 B$ ). The slopes of kinetic curves $\left(I_{\mathrm{QD}} / I_{\mathrm{QD}-\mathrm{RCP}}\right)$ indicate the rate of substrate cleavage by caspase- 1 ; these rates were different in the cell samples exposed to these treatments. However, there was consistently increased cleavage (about 3-4 times) in cells exposed to LPS and LPS-QD than in untreated control cells (Figure 5B). The fold increase in the caspase- 1 activity by LPS stimulation is comparable to the results obtained by the commercially available assay (Figure 5B). It was also found that in samples 
exhibiting a high caspase- 1 activity rate (LPS and LPS-QD treated cells, or high cell numbers) the cleavage process slowed down after some minutes (depending on the enzyme concentration), most likely due to substrate depletion. Untreated cells, however, at low concentration $\left(0.125 \times 10^{6}\right.$ cells $)$ displayed a steady enzyme activity rate for the entire time of the measurement (90 min) (Figure 5C and Figure S4). Interestingly, in the lysates of QD-DHLA-treated cells, caspase- 1 activity was somewhat lower than the values obtained for the untreated control cells suggesting the reduction of basal caspase- 1 activity by DHLA. As expected, adding a caspase-1 inhibitor, Z-WEHDFMK, to the cell lysates resulted in a significant decrease of the slope of $I_{\mathrm{QD}} / l_{\mathrm{QD}-\mathrm{RCP}}$ in the control cell lysates (Figure $5 \mathrm{C}$ ). The decrease was proportional to the concentration of the inhibitor (200 and $400 \mu \mathrm{M}$ Z-WEHD-FMK, Figure 5C). Control experiments for the caspase- 1 activity measurements in vitro (in the absence of cell lysate or in the absence of sensor) showed no changes in the ratio of $I_{\mathrm{QD}} / l_{\mathrm{QD}-\mathrm{RCP}}$ (Figure S3). On the basis of the estimated concentration of substrate in each biological sample (370 pM), we determined the caspase- 1 activity to be $19 \mathrm{pmol} / \mathrm{min}$ per $10^{6} \mathrm{microglia}$.

It is important to note that, while colorimetric assays detected a similar fold increase of caspase- 1 activity in LPS stimulated cells, they require $2 \times 10^{6}$ cells for the test; with our sensor, we were able to measure the change in enzyme activity from $0.125 \times 10^{6}$ cells (Figure 5C and Figure S4). Fluorometric tests (Caspalux 1) are more sensitive than colorimetric assays, but the recommended cell number $\left(0.5-1 \times 10^{6}\right.$ cells) is still about 4 times higher than what our sensor require. Another asset of our assay is the extremely small amount of sensor needed for a single measurement. The commercial assays required $10-50 \mu \mathrm{M}$ substrate concentrations as compared to the nanomolar concentrations used in our assay.

To evaluate the function of the nanosensor in vivo, we injected the nanosensors directly into the brain parenchyma or by intraperitoneal (ip) injections in hairless nonimmunosuppressed mice SKH-1. Intraperitoneal injection of LPS had been frequently used to induce systemic inflammation in vivo. The dosage of LPS administered ranges from $10 \mu \mathrm{g}$ to $80 \mathrm{mg} / \mathrm{kg}$, and the inflammatory response elicited differs greatly depending on the dosage and the duration of the treatment. Bolus doses of LPS ( $>50 \mathrm{mg} / \mathrm{kg}$ ) could be administered ip to induce inflammatory responses in the central nervous system, ${ }^{63}$ but the effects in the brain are insignificant when compared to the widespread systemic inflammation in the peripheral organs. ${ }^{64}$ Accumulation of systemic inflammation can induce septic shock, which in turn is lethal to the organism. In contrast, intraparenchymal or intracerebroventricular injections, though more invasive methods, are more direct routes of LPS delivery to the brain.
Intraparenchymal administration of LPS induces an immediate increase in the overall expression of its cognate receptor CD14, and a delayed but robust activation of microglia and astroglia in the brain. ${ }^{65,66}$ The expression of TLR-4 in murine brain microglia is surprisingly low in comparison to CD14, but little is known regarding the signal transduction pathways triggered by the binding of CD14 with LPS. Recent evidence suggests the involvement of NF- $\kappa$ B signaling downstream of CD14 activation, which is in analogous with TLR-4 signals in the macrophages. ${ }^{65}$ The need for a reliable sensor is, therefore, great for the detection of inflammatory mechanisms in live animals.

Caspase-1 activity was measured in nave (nontreated), LPS or LPS-QD primed animals (Figure 6). The fluorescence intensity from cleaved nanosensors was plotted against the intensity measured from uncleaved nanosensors. Using this ratio, the extent of caspase-1 activation was compared between the various groups (Figure 6B). The instrument's limitations required that we used a $480 \mathrm{~nm}$ laser excitation and emission filters of 530 and $600 \mathrm{~nm}$ (both with $50 \mathrm{~nm}$ bandpass) for cleaved and uncleaved nanosensors, respectively. The fluorescence intensity measured at $530 \mathrm{~nm}$ increased significantly $1 \mathrm{~h}$ after LPS injection and peaked at $2 \mathrm{~h}$ $(2.35 \pm 0.27, p<0.05$ when compared to animals treated with the nanosensor alone (Figure 6B). This transient increase in the peak ratios diminished at $3 \mathrm{~h}$ and returned to baseline values after $4 \mathrm{~h}$. Induction of caspase- 1 activity by LPS-QD resulted in similar changes, but it occurred with a 2-h delay, as compared to LPS alone. This delay is due to the different intracellular signals following the LPS and LPS-QD internalizations. LPS binds to TLR-4 receptors to initiate intracellular signals resulting in an increased expression of inflammatory genes such as IL- $1 \beta$. The LPSbound TLR-4 receptors are then internalized and the endotoxin is degraded and cleared from circulation. ${ }^{67}$ LPS-QDs trigger inflammatory gene expression in a similar way by activating TLR-4 receptors on the cell surface. The difference is, however, in the steps following internalization of the nanostructure. LPS-QDs, along with other types of QDs and nanoparticles, are internalized and reach the lysosomes but are not degraded as rapidly as LPS alone due to their composition and larger size. This state of "frustrated phagocytosis" leads to the disruption of lysosomes and subsequently initiates the activation of NLRP-3 receptors to form inflammasomes. ${ }^{2}$ The delayed but robust increase in caspase- 1 activity by LPS-QDs is thus likely due to the activation of inflammasome resulting from the frustrated phagocytosis.

After the peak fluorescence of the sensor, the signal was significantly reduced. This decrease in peak ratios was likely due to the quenching or disappearance of QD luminescence as the nanoparticles are cleared. These in vivo observations are in line with the 
A

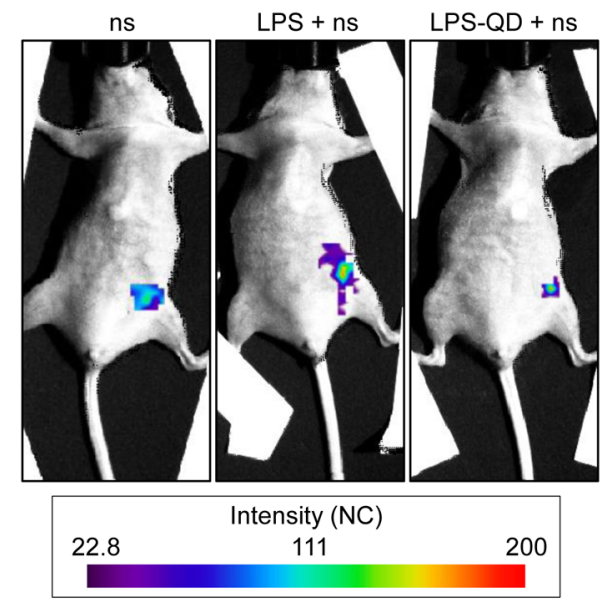

B

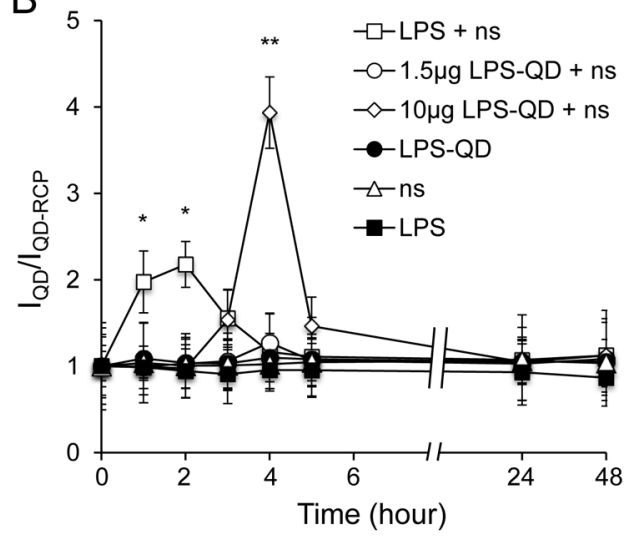

C

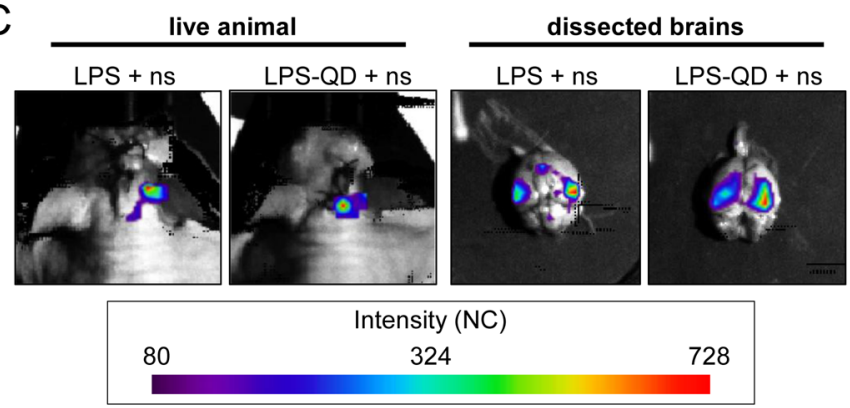

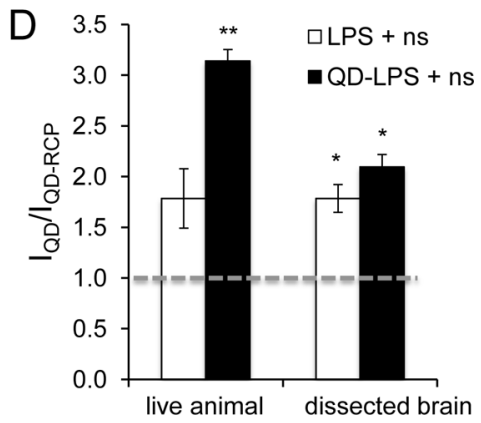

Figure 6. Detection of caspase-1 activity in vivo using the nanosensor. (A) Real-time live fluorescence images of animals after intraperitoneal injection of the nanosensors in the presence of $\operatorname{LPS}(1.5 \mu \mathrm{g})$ or LPS-QD $(1.5 \mu \mathrm{g})$ at $2 \mathrm{~h}$. Fluorescence intensity is indicated as the number of counts (NC). (B) Fluorescence intensities of the nanosensors measured in live animals injected with LPS $(1.5 \mu \mathrm{g})$ or LPS-QD $(1.5 \mu \mathrm{g}$ or $10 \mu \mathrm{g})$ in the presence or absence of the nanosensor. (C) Real-time fluorescence images of live mice following cortical devascularization and subsequent intraparenchymal injections of the nanosensors in the presence of LPS $(1.5 \mu \mathrm{g})$ or LPS $-\mathrm{QD}(1.5 \mu \mathrm{g})$. Fluorescence images of the dissected brains are also captured. $\mathrm{ns}=$ nanosensor, QD-RCP; LPS = lipopolysaccharide. (D) Fluorescence intensities of the nanosensors measured in the live animals and in the dissected brains $2 \mathrm{~h}$ after the injections. $I_{\mathrm{QD}}$ and $I_{\mathrm{QD}-\mathrm{RCP}}$ indicate fluorescence intensities measured at $480 \mathrm{~nm} / 530 \mathrm{~nm}$ (ex/em) and $480 \mathrm{~nm} / 600 \mathrm{~nm}$, respectively. The ratio between $I_{\mathrm{QD}}$ and $I_{\mathrm{QD}-\mathrm{RCP}}$ is expressed as fold increase compared with time zero (set as 1.0 , dotted line). Values represent means \pm SEM from duplicate measurements. Single asterisk $\left(^{*}\right)$ indicates significance $(p<$ 0.01 ), and double asterisk $(* *)$ indicates $p<0.05 . n=3$ animals for each treatment group. Values represent means \pm SEM from duplicate measurements. Single asterisk $\left(^{*}\right)$ indicates significance $(p<0.01)$, and double asterisk $\left.{ }^{* *}\right)$ indicates $p<0.05$, when compared with time zero. $n=5$ animals for each treatment group.

measurements of caspase- 1 activity in cell lysates. The nanosensor seems to be stable for at least several hours, since the signal for active caspase- 1 was detected after $4 \mathrm{~h}$ in LPS-QD-treated mice. In addition to evaluating fluorescence intensities of the sensor, data collection could also include measurements of the fluorescence lifetime of the QD signal in vivo. The advantage of using fluorescence lifetime in real-time imaging is two-fold: (i) Gating at longer lifetimes can prevent autofluorescence from interfering with the desired fluorescence signal. ${ }^{68}$ (ii) Changes in lifetime with time can be an additional indicator of the progression of inflammation in the target region. ${ }^{18}$

These findings suggest that our caspase- 1 nanosensor is suitable for the in vivo detection and measurements of the enzymatic activity.

The overall data support our proposal that in the present studies the activation of the microglia by LPS or LPS-QD led to the formation of the inflammasome and to the activation of the caspase- 1 , which then converted pro-IL- $1 \beta$ to its mature form IL- $1 \beta ., 33,61$ These mechanisms are illustrated in Scheme 1. Briefly, inflammasome formation occurred because of several stimuli: (i) Receptor-initiated signal transduction upon LPS binding to TLR-4. This was initiated both by LPS alone and LPS-modified QDs. (ii) LPS and LPS-QDs are internalized by the microglia and reach the lysosomal compartments. (iii) Reactive oxygen species generated during the microglia activation by LPS and LPS-QDs due to the mitochondrial impairments. ${ }^{69}$ (iv) Release of phago-lysosomal content subsequent to the swelling and eventual bursting of the lysosomes, which would trigger the formation of inflammasomes and activation of caspase-1. An interesting observation was that caspase- 1 activation by LPS in vivo was significantly faster (reaching a maximum at $2 \mathrm{~h}$ ) than caspase- 1 activation by LPS-QDs (maximum at $4 \mathrm{~h}$ ). The delay in caspase- 1 activation by LPS-QDs could be explained by the delayed release of LPS-QDs from the phagolysosomes. These findings suggest that LPS-QD could 
be usefully employed in the investigation of locally controlled inflammatory responses. Finally, the nanosensor described would seem to be useful for the detection and measurement of the onset and the rate of caspase- 1 activation in vitro, and, in real time, in vivo.

\section{CONCLUSIONS}

The findings reported here could be of wide clinical relevance; for instance, inflammation is common in many diseases and a more effective therapeutic intervention would be generally achieved if the pathological changes (e.g., activity of caspase-1) were detected early in the pathological process. Well-characterized nanocrystals allow the construction of different nanosensors relevant to inflammation. Our nanosensor can be used for the in vivo detection of caspase-1 activity, in real time, not easily achievable with currently commercially available assays. This nanosensor can also be used for the assessment of the effectiveness of novel caspase- 1 inhibitors and for the screening of various anti-inflammatory therapeutics in vitro and in vivo. However, there are still some limitations to be overcome (e.g., emission in nonoptimal spectral regions); these limitations can, however, be avoided by using nanocrystals emitting in the near-infrared spectrum and by lifetime determinations. Indeed, our preliminary lifetime measurements of QD are promising but require further optimization. The adequate instrumentation for lifetime measurements in whole animals is not commonly used in biological laboratories and their applications are only now emerging. Furthermore, sensor modifications will be required to measure the enzymatic activity for long-term measurements in the central nervous system where multiple injections are undesirable. We are currently exploring the possibility of improving the properties of the nanosensor by employing near-infrared QDs, and eventually nonmetallic nanoparticles. Alternatively, gold nanoparticles could be used instead of QDs to take advantage of plasmon resonance energy transfer (PRET). ${ }^{70,71}$

\section{MATERIALS AND METHODS}

Materials. Water was deionized using a Millipore system. All chemicals were purchased from Sigma-Aldrich, unless specified otherwise. Dihydrolipoic acid (DHLA) was prepared by reduction of thioctic acid following a known procedure. ${ }^{72}$ Tetradecylphosphonic acid (TDPA) was purchased from PCI Synthesis. All chemicals were used directly without any further purification unless otherwise stated. Dulbecco's modified Eagle's medium (DMEM, high glucose, pyruvate; 11995) was purchased from Invitrogen. TOP/TOPO (trioctylphosphine oxide)-coated CdSe(CdZnS) core-shell QDs were synthesized and purified by a protocol based on a method developed by Pons et al., ${ }^{73}$ described in detail elsewhere. ${ }^{62}$ They were stored as a suspension in chloroform prior use.

Lipopolysaccharide (LPS) isolated from E. coli 0111:B4 (L2630) was purchased from Sigma-Aldrich (Burlington, Canada) and a $1 \mathrm{mg} / \mathrm{mL}$ stock solution was prepared in sterilized water. The dosage used in cells and in animals was calculated based on the concentration of LPS (i.e., $10 \mu \mathrm{g} / \mathrm{mL}$ of LPS-QD is equivalent to $10 \mu \mathrm{g} / \mathrm{mL}$ of LPS, which is approximately 55 endotoxin units $/ \mathrm{mL})^{74}$

The caspase-1 specific inhibitor Z-WEHD-FMK was purchased from R\&D Systems.

The rhodamine-peptide was synthesized by the McGill Sheldon Biotechnology Centre using the Fmoc chemistry solid-phase synthesis method. All the amino acids were reacted one by one followed by rhodamine- $B$, using the same procedure, on a rink amide resin via the Symphony Multiplex automated peptide synthesizer (starting with $0.25 \mathrm{mmol}$ of the resin, in dimethylformamide, DMF). Fmoc protecting group removal was achieved using a $20 \%$ piperidine solution in DMF and coupling reactions were done using $N$-[(1H-benzotriazol-1-yl)(dimethylamino)methylene]- $N$-methylmethanaminium hexafluorophosphate $\mathrm{N}$-oxide (HBTU) and 4-methylmorpholine ( 5 equiv). Cleavage and deprotection of the peptide from the resin were carried out using a trifluoroacetic acid:water:phenol (95:2.5:2.5\%) mixture. The peptide was precipitated with cold diethyl ether, washed three times with cold diethyl ether, and dried under vacuum overnight. The final product was purified by reversed phase High Performance Liquid Chromatography (HPLC) and its identity was confirmed by high resolution and high accuracy mass spectrometry (Exactive Orbitrap instrument, ThermoFisher Scientific, Department of Chemistry, McGill University). ESI-MS $m / z(-): 1162.48\left[\mathrm{M}-2 \mathrm{H}^{+}\right]^{2-}, 2325.96\left[\mathrm{M}-\mathrm{H}^{+}\right]^{-}$.
Murine microglia (N9) cells, obtained from ATCC, were seeded in Iscove's Modified Dulbecco's Medium (IMDM) (12440, Gibco) containing 5\% of fetal bovine serum (26140, Gibco) and $1 \%$ penicillin-streptomycin (15140, Gibco). Cells were maintained at $37{ }^{\circ} \mathrm{C}, 5 \% \mathrm{CO}_{2}$ in a humidified atmosphere and were grown in serum containing media for $24 \mathrm{~h}$ before cell treatments to attain confluency. Cells were used between 10 and 30 passages.

Adult male $\mathrm{SKH}-1$ hairless mice were purchased from Charles River Laboratories (Montreal, Canada). All animal protocols used in this study were approved by the McGill University Animal Care Committee and followed the guidelines of the Canadian Council on Animal Care. Animals were maintained on a 12-h light/dark cycle and allowed access to food and water ad libitum. In total, 8 adult male SKH-1 mice, weighing between 25-30 g, were used for this study.

QD Surface Modification. Dihydrolipoic acid (DHLA) or mercaptopropionic acid (MPA) ( $400 \mu \mathrm{L})$ was added to the suspension of $\mathrm{CdSe}(\mathrm{CdZnS})$ (615 or $550 \mathrm{~nm}$, respectively) in chloroform $(5 \mathrm{~mL}$, $1 \mathrm{mM}$ ). The resulting mixture was heated at $60^{\circ} \mathrm{C}$ for $1 \mathrm{~h}$. It was brought to room temperature and treated with ethanol $(5 \mathrm{~mL})$ to induce precipitation of the QDs. The mixture was subjected to centrifugation for $5 \mathrm{~min}$ at $8000 \mathrm{rpm}$. A sodium hydroxide solution $(0.01 \mathrm{M})$ was used to resuspend the QD pellet. The precipitation step with ethanol was repeated on the QDs suspended in water. The QDs were resuspended in double deionized water (DI) and stored at $4{ }^{\circ} \mathrm{C}$.

LPS-QD nanoparticles were prepared based on a method described by Betanzos et al. ${ }^{75}$ The procedure involved incorporation of hydrophobic into the hydrophobic core of LPS nanoparticles. These values are of the same order of magnitude as those of the particles described by Betanzos et al. ${ }^{75}$ Briefly, the QD solution in chloroform ( $100 \mu \mathrm{L}, 5 \mu \mathrm{M}$ of QDs) was diluted to $500 \mu \mathrm{L}$ with chloroform and added to an aqueous solution of the lipoglycan $E$. coli $0111: \mathrm{B} 4(100 \mu \mathrm{L}$, of $10 \mathrm{mg} / \mathrm{mL})$. Methanol was added dropwise to the mixture) with occasional vortexing until formation of a single liquid phase. The volume of added methanol was approximately $400 \mu \mathrm{L}$. This homogeneous mixture was evaporated to dryness under a flow of nitrogen. The solid residue was resuspended in $100 \mu \mathrm{L}$ of $\mathrm{H}_{2} \mathrm{O}$. A saturated solution of tetramethylammonium hydroxide pentahydrate $\left(\mathrm{Me}_{4} \mathrm{~N}^{+} \mathrm{OH}^{-}, 5 \mathrm{H}_{2} \mathrm{O}\right)$ was added to the suspension to adjust the $\mathrm{pH}$ to 11 (ca. $5 \mu \mathrm{L}$ ). The mixture was sonicated for $30 \mathrm{~min}$ and desalted by elution through 2 consecutive Zeba columns 
(2 mL, Pierce). The LPS-QD were then filtered on a $30000 \mathrm{Da}$ cutoff Microcon filter to remove the excess of free LPS and characterized using dynamic light scattering (DLS), asymmetrical flow field-flow fractionation (AF4), zeta potential, transmission electron microscope (TEM), and cryogenic-transmission electron microscopy (cryo-TEM). Observations confirmed that the LPS-QD size distribution was broad, with an average diameter of $59 \pm 24 \mathrm{~nm}$. Cryo-TEM images LPS-QD featured small dense dots distributed inside the spherical LPS structures, attributed to isolated or clustered QDs dispersed within the hydrophobic LPS core.

Construction of the Sensor: Attachment of the Rhodamine-Conjugated Peptide to the QDs. The dispersion of MPA modified QDs $\left(\lambda_{\mathrm{em}}=\right.$ $550 \mathrm{~nm}$ ) was ligand exchanged by incubating it with the Rhodamine-B conjugated peptide (RCP) 1:37 ratio for 2 days, with periodic sonication, at $4{ }^{\circ} \mathrm{C}$, in the dark. The construct was redispersed in DI water and stored in the dark, at $4{ }^{\circ} \mathrm{C}$ for 6 weeks.

Intraperitoneal Injections of Nanosensors, Lipopolysaccharide, and LPS-QD. For intraperitoneal (ip) injections, animals were manually restrained and held with the head inclined at a $45^{\circ}$ angle. With a $26 \mathrm{G}$ needle, animals were injected in the lower left abdomen with $50 \mu \mathrm{L}$ of nanosensor $(15 \mu \mathrm{M}), 50 \mu \mathrm{L}$ of LPS (working dose $50 \mu \mathrm{g} / \mathrm{kg}$ ), or $50 \mu \mathrm{L}$ of LPS-QD (working dose $50 \mu \mathrm{g} / \mathrm{kg}$ of LPS) alone and in combination. These doses are below the well-used dose range of LPS $(10-80 \mathrm{mg} / \mathrm{kg})$ to induce lethal septic shock. ${ }^{76}$

In Vivo Fluorescence Imaging. Real-time fluorescence imaging was carried out using the Optix MX3 imager by ART (Advanced Research Technologies, Montreal, Canada). System details are described elsewhere. ${ }^{77}$ Briefly, after ip injections, animals were first anesthetized in an isoflurane-filled chamber, and then placed in the supine position on the 5-mouse scanning bed. Anesthesia (isoflurane) was maintained for the duration of the imaging process. A multiphoton laser was selected for the excitation of the nanosensor. For cleaved nanosensors, the excitation was selected at $480 \mathrm{~nm}$, and the $530 \mathrm{~nm}$ band-pass $50 \mathrm{~nm}$ filter was used for photon collection. For uncleaved nanosensors, the excitation was at $480 \mathrm{~nm}$, and the $600 \mathrm{~nm}$ band-pass $50 \mathrm{~nm}$ filter was used. Animals were imaged immediately after ip injections, and then imaged again every hour $(1-5 \mathrm{~h})$ and at $24 \mathrm{~h}$ after injection.

QD Characterization. AF4/UV-VIS/Fluo/MALS+QELS system. The principle of asymmetrical flow field-flow fractionation (AF4) has been described elsewhere. ${ }^{78}$ An AF4 system (AF 2000 MT, Postnova Analytics, Salt Lake City, UT) with a channel thickness of $350 \mu \mathrm{m}$ was connected inline to a UV-VIS variable wavelength spectrophotometric detector (SPD-20A, Postnova Analytics), a fluorescence detector (RF-10A $\mathrm{XL}_{\mathrm{X}}$, Postnova Analytics), a multiangle light scattering detector (MALS, Dawn Heleos 8+, Wyatt Technology, Santa Barbara, (A), and a quasi-elastic light scattering (QELS) detector (WyattQELS, Wyatt Technology) which is an add-on unit connected to the $90^{\circ}$ angle of the MALS Dawn Heleos 8+ detector. The MALS was equipped with a K5 cell and a GaAs laser operating at $658 \mathrm{~nm}$ taking measurements at $1 \mathrm{~s}$ intervals. Data collection and analysis were done using ASTRA version 5.3.4.20 (Wyatt Technology). The channel was fitted with a regenerated cellulose membrane (10 kDa cutoff, RC, Z-MEM-AQU-627, Postnova Analytics) which was suitable for analysis of proteins and nanoparticles. All the flow rates were controlled by the AF2000 Control software (Postnova Analytics, Salt Lake City, UT). The cross-flow was generated by Khloen syringe pumps (Postnova Analytics) while the axial and focusing flows were delivered by isocratic pumps (PN1130, Postnova Analytics).

AF4 Separation Conditions for QDs Alone. The carrier medium was prefiltered $(0.1 \mu \mathrm{m})$ deionized water. After flow equilibration, the sample was injected with a flow rate of $0.2 \mathrm{~mL} / \mathrm{min}$ (injection loop volume: $21.5 \mu \mathrm{L}$ ), followed by a 6 min-focusing step with a cross-flow rate of $1.2 \mathrm{~mL} / \mathrm{min}$ and a detector flow rate of $0.3 \mathrm{~mL} / \mathrm{min}$. Following a $1 \mathrm{~min}$ transition, a two-step cross-flow rate gradient was initiated for the elution mode. The starting cross-flow rate $(1.2 \mathrm{~mL} / \mathrm{min})$ was decreased linearly to $0.0 \mathrm{~mL} / \mathrm{min}$ within $20 \mathrm{~min}$. The cross-flow rate was then kept constant at $0.0 \mathrm{~mL} / \mathrm{min}$ for $15 \mathrm{~min}$ to allow elution of any large agglomerates. The detector flow rate was kept at $0.3 \mathrm{~mL} / \mathrm{min}$ throughout. The detection of the eluted fractionated QDs/ agglomerates was performed sequentially by UV absorbance at $280 \mathrm{~nm}$, fluorescence with $\lambda_{\text {ex }} 365 \mathrm{~nm}$ and $\lambda_{\text {em }} 615 \mathrm{~nm}$, MALS and QELS. Each fractogram presented is representative of a triplicate sample.

AF4 Separation Conditions for the LPS-QD. The carrier medium was a solution of $\mathrm{NaCl}(20 \mathrm{mM})$. After flow equilibration, the sample was injected with a flow rate of $0.2 \mathrm{~mL} / \mathrm{min}$ (injection loop volume: $21.5 \mu \mathrm{L}$ ), followed by a 6 min-focusing with a crossflow rate of $2.0 \mathrm{~mL} / \mathrm{min}$ and a detector flow rate of $0.5 \mathrm{~mL} / \mathrm{min}$. Following a $1 \mathrm{~min}$ transition, a three-step cross-flow rate gradient was initiated for the elution mode. The cross-flow was kept constant for a period of $10 \mathrm{~min}$, before being decreased linearly from 2.0 to $0 \mathrm{~mL} / \mathrm{min}$ within $10 \mathrm{~min}$. The cross-flow rate was then kept constant at $0.0 \mathrm{~mL} / \mathrm{min}$ for another $10 \mathrm{~min}$ to allow elution of any large particles. The detector flow rate was kept at $0.5 \mathrm{~mL} / \mathrm{min}$ throughout. The detection of the eluted fractionated QDs/agglomerates was performed sequentially by UV absorbance at $280 \mathrm{~nm}$, fluorescence with $\lambda_{\text {ex }} 365 \mathrm{~nm}$ and $\lambda_{\text {em }}$ $615 \mathrm{~nm}$, MALS and DLS. Each fractogram presented is representative of a triplicate sample.

Physicochemical Characterization of QDs. UV-vis absorbance spectra were recorded $200-800 \mathrm{~nm}$ with an Agilent Diode Array Spectrophotometer model $8452 \mathrm{~A}$. The diameter of the nanoparticles and their concentration in solution were determined by measuring the wavelength and the absorbance at the first excitonic peak which were used as parameters in the empirical formulas derived by Yu et al. ${ }^{79}$ Fluorescence spectra were recorded with an Eclipse instrument from Varian Cary. The fluorescence spectra were taken on samples diluted to an absorbance at the excitation wavelength inferior to 0.1 (monochromator excitation and emission slits were set at $5 \mathrm{~nm}$; photomultiplier voltage was set at $600 \mathrm{~V}$ ). Zeta potentials of LPS-QDs surfaces were determined with a Zetasizer Nano ZS from Malvern Instruments. QDs were suspended in either double deionized water or phosphate buffer $(10 \mathrm{mM}, \mathrm{pH} 5.0$, $6.0,7.8,8.5,10.0$ ) before measurement.

Transmission Electron Microscopy. To observe the size and size distribution of the LPS-QD nanoparticles, one drop of a dilute sample of the quantum dot-LPS solution in water was placed onto a Formvar-coated copper grid and allowed to settle for $15 \mathrm{~min}$. The excess of solvent was wicked away using an absorbent pad. The samples were imaged on a FEI Tecnai 12, $120 \mathrm{kV}$ with a Gatan 792 Bioscan 1k $\times 1 \mathrm{k}$ Wide Angle Multiscan CCD Camera at the Facility for Electron Microscopy Research of the Anatomy and Cell Biology department at McGill University.

The structures of the prepared LPS-QD in solution were observed by cryo-transmission electron microscopy (FEl Titan Krios operated at $300 \mathrm{kV}$ (ryo-STEM). The images were acquired using a Gatan Ultrascan $40004 \mathrm{k} \times 4 \mathrm{k}$ CCD Camera System at the Facility for Electron Microscopy Research of the Anatomy and Cell Biology department at McGill University.

Cell Treatments. Media was aspirated and cells were pretreated in serum-free media with TLR-4 signaling inhibitor (CLI-095, InvivoGen) $(250 \mathrm{nM}, 30 \mathrm{~min})$ and/or treated with lipopolysaccharide-QD nanoparticle (LPS-QD) $(10 \mu \mathrm{g} / \mathrm{mL}, 24 \mathrm{~h})$. Cells were treated with lipopolysaccharide (LPS) $(10 \mu \mathrm{g} / \mathrm{mL}, 24 \mathrm{~h})$ (L-2630, Sigma) or Antimycin A (Sigma, A8674) $(1 \mu \mathrm{M}, 24 \mathrm{~h})$ as negative controls for nitric oxide (NO) release and MTT assay. For caspase-1 activity measurements with the nanosensor, the $\mathrm{N} 9$ cells were treated with LPS-QD $(100 \mathrm{ng} / \mathrm{mL}), \mathrm{QD}-\mathrm{DHLA}$ $(0.31 \mathrm{nM})$, and LPS $(100 \mathrm{ng} / \mathrm{mL})$ for $24 \mathrm{~h}$; then the cells were counted and lysed by freezing. A total of $(0.125-0.5) \times 10^{6}$ cells were used for the caspase- 1 activity measurements with the QD-RCP nanosensor. The fluorescence spectra were recorded using an Eclipse instrument from Varian Cary.

Cell Viability. Mitochondrial metabolic activity of cells was measured using MTT assay. Cells were seeded in 24-well plates (3526, Costar) at a density of $2 \times 10^{5}$ cells/well. Following treatment, media was removed and replaced with fresh serum-free media (500 $\mu \mathrm{L} /$ well). MTT solution $(0.5 \mathrm{mg} / \mathrm{mL}$ ) (M2128, Sigma) was added to each well and incubated for $30 \mathrm{~min}$ at $37^{\circ} \mathrm{C}$. Formazan crystals were formed then dissolved by adding dimethyl sulfoxide (DMSO, 154938, Sigma) and quantified by 
measuring the absorbance of the solution at $595 \mathrm{~nm}$ using Benchmark microplate reader (Bio-Rad, Canada). The extent of formazan conversion is expressed in percentages relative to the untreated control and normalized to the cell numbers. Results are expressed as mean \pm SEM obtained from at least three independent experiments performed in triplicate.

Nitric 0xide Release. Nitric oxide released from treated cells was measured using Griess reagent (G4410, Sigma). Briefly, cells were seeded in 24-well plates (3526, Costar) at a density of $2 \times$ $10^{5}$ cells/well. Following treatment, $50 \mu \mathrm{L}$ of cell supernatant from each well was collected and transferred to a new plate. A total of $50 \mu \mathrm{L}$ of Griess reagent was added to each well and incubated at room temperature for $15 \mathrm{~min}$. Absorbance of the produced nitrite was measured using the spectrophotometer at $540 \mathrm{~nm}$. Results are expressed as mean \pm SEM obtained from at least three independent experiments performed in triplicate.

Enzyme-Linked Immunosorbent Assays. Cells were seeded in 24well plates $\left(3526\right.$, Costar) at a density of $1 \times 10^{5}$ cells/well. Production of IL- $1 \beta$ was assessed using a commercial ELISA kit (SMLB00C, R\&D Systems). Briefly, following treatment the supernatants were collected and the amount of cytokine released into the media was quantified according to the supplier's protocol. Results are expressed as mean \pm SEM obtained from at least three independent experiments performed in triplicate.

LPS-QD Uptake by Fluorescent Microscopy. Cells were seeded at a density of $5 \times 10^{4}$ cells/well in 24-well plates (3526, Costar). Following treatment, media was aspirated and cells were washed once with $1 \times$ PBS, fixed by adding paraformaldehyde (PFA) $4 \%$ (29447, BDH), and incubated for $15 \mathrm{~min}$ at room temperature. Cells were then washed three times with $1 \times$ PBS and nuclei were stained with Hoechst 33342 (H1399, Invitrogen) $(10 \mu \mathrm{M}$, $10 \mathrm{~min}$ ). Fluorescence micrographs were acquired with a Leica DFC350FX monochrome digital camera connected to a Leica DMI4000B inverted fluorescence microscope using a DAPI1160A (Nuclei) and CYS3 (LPS-QD) filters. Images were acquired in gray scale using Leica Application Suite (LAS). The average number of LPS-QD per cell was counted and analyzed using ImageJ software. Results are expressed as mean \pm SEM obtained from at least three independent experiments performed in triplicate.

Lipid Droplet Staining. For lipid droplet staining, cells were seeded on confocal chamber slides (Lab-Tek, Nalge Nunc International, Rochester, NY) at a density of $1.5 \times 10^{4}$ cells/well (area of well $=0.8 \mathrm{~cm}^{2}$ ). After treatments, cells were fixed with PFA (4\%) and LDs were stained with HCS LipidTOX (Invitrogen, H34477), a deep red neutral lipid stain. HCS LipidTOX (diluted 200 -fold in PBS) was added for $30 \mathrm{~min}$ at room temperature. At this point, cells were protected from light. Cells were washed with PBS prior to imaging.

Confocal Microscopy. All confocal images were acquired with a Zeiss LSM 510 NLO inverted confocal microscope using a Plan Achromat $63 \mathrm{X} / 1.4$ Oil DIC objective. Images of HCS LipidTOXlabeled LDs were acquired using a $\mathrm{HeNe} 633 \mathrm{~nm}$ laser and a long pass (LP) 650 filter. Alexa Fluor 488 conjugated secondary antibody was imaged using Argon $488 \mathrm{~nm}$ excitation laser and a 500-550 band-pass (BP) filter. LPS-QD nanoparticles were detected using a HeNe $543 \mathrm{~nm}$ excitation laser and a BP 565-615 IR filter. All images were acquired at a resolution of $1024 \times 1024$ pixels.

Immunocytochemistry of LAMP-1. Cells were seeded on coverslips (area $=1.1 \mathrm{~cm}^{2}$ ) (Fisher) at a density of $2 \times 10^{4}$ cells/ coverslip. Prior to seeding, coverslip surfaces were coated with rat tail collagen (Sigma, C7661). Paraformaldehyde-fixed cells were permeabilized with Triton X-100 (0.1\%) (Amersham Biosciences, \# 17-1315-01) for $5 \mathrm{~min}$ and then blocked with goat serum (10\%) (Sigma, G9023) for $1 \mathrm{~h}$ at room temperature. Cells were incubated overnight $\left(4^{\circ} \mathrm{C}\right)$ with a primary antibody against LAMP-1 (rabbit polyclonal, dilution 1:500) (Abcam, ab24170), followed by an incubation ( $1 \mathrm{~h}$, room temperature) with antirabbit (goat) secondary antibody (conjugated to Alexa Fluor 488) (Invitrogen, A-11008). Coverslips were mounted on glass microscope slides (Fisher Scientific, 12-550-14) using AquaPoly/Mount (Polysciences, Inc., \# 18-606).

Statistical Analysis. All experiments were performed at least twice and all samples were analyzed in triplicates. Data are expressed as means \pm SEM and analyzed by ANOVA using Tukey's and Dunnett's post hoc test for multiple comparisons. Significant differences are indicated by asterisks, ${ }^{*} p<0.05,{ }^{* *} p<$ 0.01 .

Conflict of Interest: The authors declare no competing financial interest.

Acknowledgment. The authors declare no conflicts. The authors would like to thank N. Al-Hajaj for performing the biochemical assays in microglia and the Facility for Electron Microscopy Research (FEMR) at McGill University for the assistance in the use of their instruments. This work was supported by the Canadian Institutes of Health Research.

Supporting Information Available: A schematic of the construction of the sensor, biological characterization of the QD-DHLA, control experiments for the caspase-1 activity measurements in vitro and activity of caspase- 1 as a function of cell number. This material is available free of charge via the Internet at http://pubs.acs.org.

\section{REFERENCES AND NOTES}

1. Strowig, T.; Henao-Mejia, J.; Elinav, E.; Flavell, R. Inflammasomes in Health and Disease. Nature 2012, 481, 278286.

2. Demento, S. L.; Eisenbarth, S. C.; Foellmer, H. G.; Platt, C.; Caplan, M. J.; Mark Saltzman, W.; Mellman, I.; Ledizet, M.; Fikrig, E.; Flavell, R. A.; et al. Inflammasome-Activating Nanoparticles as Modular Systems for Optimizing Vaccine Efficacy. Vaccine 2009, 27, 3013-3021.

3. Franchi, L.; Eigenbrod, T.; Munoz-Planillo, R.; Nunez, G. The Inflammasome: A Caspase-1-Activation Platform That Regulates Immune Responses and Disease Pathogenesis. Nat. Immunol. 2009, 10, 241-247.

4. Latz, E. The Inflammasomes: Mechanisms of Activation and Function. Curr. Opin. Immunol. 2010, 22, 28-33.

5. Martinon, F.; Petrilli, V.; Mayor, A.; Tardivel, A.; Tschopp, J. Gout-Associated Uric Acid Crystals Activate the NALP3 Inflammasome. Nature 2006, 440, 237-241.

6. Yazdi, A. S.; Guarda, G.; Riteau, N.; Drexler, S. K.; Tardivel, A.; Couillin, I.; Tschopp, J. Nanoparticles Activate the NLR Pyrin Domain Containing 3 (NLRP3) Inflammasome and Cause Pulmonary Inflammation Through Release of IL1 alpha and IL-1beta. Proc. Natl. Acad. Sci. U.S.A. 2010, 107, 19449-19454.

7. Freche, B.; Reig, N.; van der Goot, F. G. The Role of the Inflammasome in Cellular Responses to Toxins and Bacterial Effectors. Semin. Immunopathol. 2007, 29, 249-260.

8. Vallhov, H.; Qin, J.; Johansson, S. M.; Ahlborg, N.; Muhammed, M. A.; Scheynius, A.; Gabrielsson, S. The Importance of an Endotoxin-Free Environment During the Production of Nanoparticles Used in Medical Applications. Nano Lett. 2006, 6, 1682-1686.

9. Smulders, S.; Kaiser, J. P.; Zuin, S.; Van Landuyt, K. L.; Golanski, L.; Vanoirbeek, J.; Wick, P.; Hoet, P. H. Contamination of Nanoparticles by Endotoxin: Evaluation of Different Test Methods. Part. Fibre Toxicol. 2012, 9, 41.

10. Sandberg, W. J.; Lag, M.; Holme, J. A.; Friede, B.; Gualtieri, M.; Kruszewski, M.; Schwarze, P. E.; Skuland, T.; Refsnes, M. Comparison of Non-Crystalline Silica Nanoparticles in IL1beta Release from Macrophages. Part. Fibre Toxicol. 2012, 9, 32

11. Magalhaes, P. O.; Lopes, A. M.; Mazzola, P. G.; Rangel-Yagui, C.; Penna, T. C. V.; Pessoa, A. Methods of Endotoxin Removal from Biological Preparations: A Review. J. Pharm. Pharm. Sci. 2007, 10, 388-404.

12. Mistry, A.; Stolnik, S.; Illum, L. Nanoparticles for Direct Nose-to-Brain Delivery of Drugs. Int. J. Pharm. 2009, 379, 146-157.

13. Herbert, R. P.; Harris, J.; Chong, K. P.; Chapman, J.; West, A. K.; Chuah, M. I. Cytokines and Olfactory Bulb Microglia in Response to Bacterial Challenge in the Compromised Primary Olfactory Pathway. J. Neuroinflammation 2012, 9, 109. 
14. Medintz, I. L.; Clapp, A. R.; Brunel, F. M.; Tiefenbrunn, T.; Uyeda, H. T.; Chang, E. L.; Deschamps, J. R.; Dawson, P. E.; Mattoussi, H. Proteolytic Activity Monitored by Fluorescence Resonance Energy Transfer Through Quantum-DotPeptide Conjugates. Nat. Mater. 2006, 5, 581-589.

15. Algar, W. R.; Ancona, M. G.; Malanoski, A. P.; Susumu, K.; Medintz, I. L. Assembly of a Concentric Forster Resonance Energy Transfer Relay on a Quantum Dot Scaffold: Characterization and Application to Multiplexed Protease Sensing. ACS Nano 2012, 6, 11044-11058.

16. Zhang, Y.; Wang, T. H. Quantum Dot Enabled Molecular Sensing and Diagnostics. Theranostics 2012, 2, 631-54

17. Shi, L.; De Paoli, V.; Rosenzweig, N.; Rosenzweig, Z. Synthesis and Application of Quantum Dots FRET-Based Protease Sensors. J. Am. Chem. Soc. 2006, 128, 1037810379.

18. Orte, A.; Alvarez-Pez, J. M.; Ruedas-Rama, M. J. Fluorescence Lifetime Imaging Microscopy for the Detection of Intracellular $\mathrm{pH}$ with Quantum Dot Nanosensors. ACS Nano 2013, 7, 6387-6395.

19. Wu, C. S.; Khaing Oo, M. K.; Fan, X. Highly Sensitive Multiplexed Heavy Metal Detection Using Quantum-DotLabeled DNAzymes. ACS Nano 2010, 4, 5897-5904.

20. Zhang, C. Y.; Yeh, H. C.; Kuroki, M. T.; Wang, T. H. SingleQuantum-Dot-Based DNA Nanosensor. Nat. Mater. 2005, 4, 826-831.

21. Lewinski, N.; Colvin, V.; Drezek, R. Cytotoxicity of Nanoparticles. Small 2008, 4, 26-49.

22. Winnik, F. M.; Maysinger, D. Quantum Dot Cytotoxicity and Ways To Reduce It. Acc. Chem. Res. 2012, 46, 672-680.

23. Lovric, J.; Cho, S. J.; Winnik, F. M.; Maysinger, D. Unmodified Cadmium Telluride Quantum Dots Induce Reactive Oxygen Species Formation Leading to Multiple Organelle Damage and Cell Death. Chem. Biol. 2005, 12, 1227-1234.

24. Jaiswal, J. K.; Goldman, E. R.; Mattoussi, H.; Simon, S. M. Use of Quantum Dots for Live Cell Imaging. Nat. Methods 2004, 1, 73-78.

25. Medintz, I. L.; Uyeda, H. T.; Goldman, E. R.; Mattoussi, H. Quantum Dot Bioconjugates for Imaging, Labelling and Sensing. Nat. Mater. 2005, 4, 435-446.

26. Mattoussi, H.; Palui, G.; Na, H. B. Luminescent Quantum Dots as Platforms for Probing in Vitro and in Vivo Biological Processes. Adv. Drug Delivery Rev. 2012, 64, 138-166.

27. Hotzer, B.; Medintz, I. L.; Hildebrandt, N. Fluorescence in Nanobiotechnology: Sophisticated Fluorophores for Novel Applications. Small 2012, 8, 2297-2326.

28. Delehanty, J. B.; Susumu, K.; Manthe, R. L.; Algar, W. R.; Medintz, I. L. Active Cellular Sensing with Quantum Dots: Transitioning from Research Tool to Reality; A Review. Anal. Chim. Acta 2012, 750, 63-81.

29. Liu, C.-W.; Chang, H.-T. Protein-Conjugated Quantum Dots for Detecting Trypsin and Trypsin Inhibitor through Fluorescence Resonance Energy Transfer. Open Anal. Chem. J. 2007, 1, 1-6.

30. Biswas, P.; Cella, L. N.; Kang, S. H.; Mulchandani, A.; Yates, M. V.; Chen, W. A Quantum-Dot Based Protein Module for in Vivo Monitoring of Protease Activity through Fluorescence Resonance Energy Transfer. Chem. Commun. 2011, 47, 5259-5261.

31. Boeneman, K.; Mei, B. C.; Dennis, A. M.; Bao, G.; Deschamps, J. R.; Mattoussi, H.; Medintz, I. L. Sensing Caspase 3 Activity with Quantum Dot-Fluorescent Protein Assemblies. J. Am. Chem. Soc. 2009, 131, 3828-3829.

32. Tang, A.; Mei, B.; Wang, W.; Hu, W.; Li, F.; Zhou, J.; Yang, Q.; Cui, H.; Wu, M.; Liang, G. FITC-Quencher Based, Caspase 3-Activatable Nanoprobes for Effectively Sensing Caspase 3 in Vitro and in Cells. Nanoscale 2013, 5, 8963-8967.

33. Suzuki, M.; Husimi, Y.; Komatsu, H.; Suzuki, K.; Douglas, K. T. Quantum Dot FRET Biosensors That Respond to $\mathrm{pH}$, to Proteolytic or Nucleolytic Cleavage, to DNA Synthesis, or to a Multiplexing Combination. J. Am. Chem. Soc. 2008, 130, 5720-5725.

34. Sapsford, K. E.; Granek, J.; Deschamps, J. R.; Boeneman, K.; Blanco-Canosa, J. B.; Dawson, P. E.; Susumu, K.; Stewart, M. H.; Medintz, I. L. Monitoring Botulinum Neurotoxin A
Activity with Peptide-Functionalized Quantum Dot Resonance Energy Transfer Sensors. ACS Nano 2011, 5, 26872699.

35. Nakahira, K.; Haspel, J. A.; Rathinam, V. A.; Lee, S. J.; Dolinay, T.; Lam, H. C.; Englert, J. A.; Rabinovitch, M.; Cernadas, M.; Kim, H. P.; et al. Autophagy Proteins Regulate Innate Immune Responses by Inhibiting the Release of Mitochondrial DNA Mediated by the NALP3 Inflammasome. Nat. Immunol. 2011, 12, 222-230.

36. Lunov, O.; Syrovets, T.; Loos, C.; Nienhaus, G. U.; Mailander, V.; Landfester, K.; Rouis, M.; Simmet, T. Amino-Functionalized Polystyrene Nanoparticles Activate the NLRP3 Inflammasome in Human Macrophages. ACS Nano 2011, 5 , 9648-9657.

37. Vacha, R.; Martinez-Veracoechea, F. J.; Frenkel, D. Intracellular Release of Endocytosed Nanoparticles Upon a Change of Ligand-Receptor Interaction. ACS Nano 2012, 6, 10598-10605.

38. Choi, A. O.; Cho, S. J.; Desbarats, J.; Lovric, J.; Maysinger, D. Quantum Dot-Induced Cell Death Involves Fas Upregulation and Lipid Peroxidation in Human Neuroblastoma Cells. J. Nanobiotechnol. 2007, 5, 1.

39. Lovric, J.; Cho, S. J.; Winnik, F. M.; Maysinger, D. Unmodified Cadmium Telluride Quantum Dots Induce Reactive Oxygen Species Formation Leading to Multiple Organelle Damage and Cell Death. Chem. Biol. 2005, 12, 1227-1234.

40. Foster, K. A.; Galeffi, F.; Gerich, F. J.; Turner, D. A.; Muller, M. Optical and Pharmacological Tools to Investigate the Role of Mitochondria During Oxidative Stress and Neurodegeneration. Prog. Neurobiol. 2006, 79, 136-171.

41. Maysinger, D.; Lovric, J.; Eisenberg, A.; Savic, R. Fate of Micelles and Quantum Dots in Cells. Eur. J. Pharm. Biopharm. 2007, 65, 270-81.

42. Lalancette-Hebert, M.; Moquin, A.; Choi, A. O.; Kriz, J.; Maysinger, D. Lipopolysaccharide-QD Micelles Induce Marked Induction of TLR2 and Lipid Droplet Accumulation in Olfactory Bulb Microglia. Mol. Pharmaceutics 2010, 7, 1183-1194.

43. Liao, P. C.; Chao, L. K.; Chou, J. C.; Dong, W. C.; Lin, C. N.; Lin, C. Y.; Chen, A.; Ka, S. M.; Ho, C. L.; Hua, K. F. Lipopolysaccharide/Adenosine Triphosphate-Mediated Signal Transduction in the Regulation of NLRP3 Protein Expression and Caspase-1-Mediated Interleukin-1beta Secretion. Inflammation Res. 2013, 62, 89-96.

44. Schroder, K.; Sagulenko, V.; Zamoshnikova, A.; Richards, A. A.; Cridland, J. A.; Irvine, K. M.; Stacey, K. J.; Sweet, M. J. Acute Lipopolysaccharide Priming Boosts Inflammasome Activation Independently of Inflammasome Sensor Induction. Immunobiology 2012, 217, 1325-1329.

45. Kettenmann, H.; Kirchhoff, F.; Verkhratsky, A. Microglia: New Roles for the Synaptic Stripper. Neuron 2013, 77, 10-18.

46. Kierdorf, K.; Prinz, M. Factors Regulating Microglia Activation. Front. Cell. Neurosci. 2013, 7.

47. Aguzzi, A.; Barres, B. A.; Bennett, M. L. Microglia: Scapegoat, Saboteur, or Something Else? Science 2013, 339, 156-161.

48. Kettenmann, H.; Hanisch, U.-K.; Noda, M.; Verkhratsky, A. Physiology of Microglia. Physiol. Rev. 2011, 91, 461-553.

49. Nadeau, S.; Rivest, S. Endotoxemia Prevents the Cerebral Inflammatory Wave Induced by Intraparenchymal Lipopolysaccharide Injection: Role of Glucocorticoids and CD14. J. Immunol. 2002, 169, 3370-3381.

50. Iversen, T. G.; Frerker, N.; Sandvig, K. Uptake of RicinBQuantum Dot Nanoparticles by a Macropinocytosis-Like Mechanism. J. Nanobiotechnol. 2012, 10, 33.

51. Zhang, L. W.; Monteiro-Riviere, N. A. Mechanism of Quantum Dot Nanoparticle Cellular Uptake. Toxicol. Sci. 2009, 110, 138-155.

52. Duncan, R.; Richardson, S. C. Endocytosis and Intracellular Trafficking as Gateways for Nanomedicine Delivery: Opportunities and Challenges. Mol. Pharmaceutics 2012, 9, 2380-2402.

53. Brown, G. C.; Neher, J. J. Eaten Alive! Cell Death by Primary Phagocytosis: 'Phagoptosis'. Trends Biochem. Sci. 2012, 37, 325-332. 
54. Neher, J. J.; Neniskyte, U.; Brown, G. C. Primary Phagocytosis of Neurons by Inflamed Microglia: Potential Roles in Neurodegeneration. Front. Pharmacol. 2012, 3, 27.

55. Tremblay, M. E.; Stevens, B.; Sierra, A.; Wake, H.; Bessis, A.; Nimmerjahn, A. The Role of Microglia in the Healthy Brain. J. Neurosci. 2011, 31, 16064-16069.

56. Khatchadourian, A.; Bourque, S. D.; Richard, V. R.; Titorenko, V. I.; Maysinger, D. Dynamics and Regulation of Lipid Droplet Formation in Lipopolysaccharide (LPS)-Stimulated Microglia. Biochim. Biophys. Acta 2012, 1821, 607-617.

57. Melo, R. C.; D'Avila, H.; Wan, H. C.; Bozza, P. T.; Dvorak, A. M.; Weller, P. F. Lipid Bodies in Inflammatory Cells: Structure, Function, and Current Imaging Techniques. J. Histochem. Cytochem. 2011, 59, 540-556.

58. Sohaebuddin, S. K.; Tang, L. A Simple Method to Visualize and Assess the Integrity of Lysosomal Membrane in Mammalian Cells Using a Fluorescent Dye. Methods Mol. Biol. 2013, 991, 25-31.

59. Eno, C. O.; Zhao, G.; Venkatanarayan, A.; Wang, B.; Flores, E. R.; Li, C. Noxa Couples Lysosomal Membrane Permeabilization and Apoptosis During Oxidative Stress. Free Radical Biol. Med. 2013, 65, 26-37.

60. Appelqvist, H.; Waster, P.; Kagedal, K.; Ollinger, K. The Lysosome: From Waste Bag to Potential Therapeutic Target. J. Mol. Cell Biol. 2013, 5, 214-226.

61. Rathinam, V. A.; Vanaja, S. K.; Fitzgerald, K. A. Regulation of Inflammasome Signaling. Nat. Immunol. 2012, 13, 333-342.

62. Al-Hajaj, N. A.; Moquin, A.; Neibert, K. D.; Soliman, G. M.; Winnik, F. M.; Maysinger, D. Short Ligands Affect Modes of QD Uptake and Elimination in Human Cells. ACS Nano 2011, 5, 4909-4918.

63. Kouakou, K.; Schepetkin, I. A.; Jun, S.; Kirpotina, L. N.; Yapi, A.; Khramova, D. S.; Pascual, D. W.; Ovodov, Y. S.; Jutila, M. A.; Quinn, M. T. Immunomodulatory Activity of Polysaccharides Isolated from Clerodendrum Splendens: Beneficial Effects in Experimental Autoimmune Encephalomyelitis. BMC Complementary Altern. Med. 2013, 13, 149.

64. Zhou, H.; Andonegui, G.; Wong, C. H.; Kubes, P. Role of Endothelial TLR4 for Neutrophil Recruitment into Central Nervous System Microvessels in Systemic Inflammation. J. Immunol. 2009, 183, 5244-5250.

65. Nadeau, S.; Rivest, S. Endotoxemia Prevents the Cerebral Inflammatory Wave Induced by Intraparenchymal Lipopolysaccharide Injection: Role of Glucocorticoids and CD14. J. Immunol. 2002, 169, 3370-3381.

66. Rankine, E. L.; Hughes, P. M.; Botham, M. S.; Perry, V. H.; Felton, L. M. Brain Cytokine Synthesis Induced by an Intraparenchymal Injection of LPS Is Reduced in MCP-1Deficient Mice Prior to Leucocyte Recruitment. Eur. J. Neurosci. 2006, 24, 77-86.

67. Lentschat, A.; El-Samalouti, V. T.; Schletter, J.; Kusumoto, S.; Brade, L.; Rietschel, E. T.; Gerdes, J.; Ernst, M.; Flad, H.; Ulmer, A. J. The Internalization Time Course of a Given Lipopolysaccharide Chemotype Does Not Correspond to Its Activation Kinetics in Monocytes. Infect. Immun. 1999, 67, 2515-2521.

68. Choi, A. O.; Maysinger, D. Intranasal Fluorescent Nanocrystals for Longitudinal in Vivo Evaluation of Cerebral Microlesions. Pharm. Nanotechnol. 2013, 1, 93-104.

69. Hsu, H. Y.; Wen, M. H. Lipopolysaccharide-Mediated Reactive Oxygen Species and Signal Transduction in the Regulation of Interleukin-1 Gene Expression. J. Biol. Chem. 2002, 277, 22131-22139.

70. Choi, Y.; Kang, T.; Lee, L. P. Plasmon Resonance Energy Transfer (PRET)-Based Molecular Imaging of Cytochrome C in Living Cells. Nano Lett. 2009, 9, 85-90.

71. Liu, G. L.; Long, Y. T.; Choi, Y.; Kang, T.; Lee, L. P. Quantized Plasmon Quenching Dips Nanospectroscopy via Plasmon Resonance Energy Transfer. Nat. Methods 2007, 4, 10151017.

72. Clapp, A. R.; Goldman, E. R.; Mattoussi, H. Capping of CdSeZnS Quantum Dots with DHLA and Subsequent Conjugation with Proteins. Nat. Protoc. 2006, 1, 1258-1266.

73. Pons, T.; Lequeux, N.; Mahler, B.; Sasnouski, S.; Fragola, A.; Dubertret, B. Synthesis of Near-Infrared-Emitting,
Water-Soluble CdTeSe/CdZnS Core/Shell Quantum Dots. Chem. Mater. 2009, 21, 1418-1424.

74. Neibert, K.; Gosein, V.; Sharma, A.; Khan, M.; Whitehead, M. A.; Maysinger, D.; Kakkar, A. "Click" Dendrimers as AntiInflammatory Agents: With Insights into Their Binding from Molecular Modeling Studies. Mol. Pharmaceutics 2013, 10, 2502-2508.

75. Betanzos, C. M.; Gonzalez-Moa, M.; Johnston, S. A.; Svarovsky, S. A. Facile Labeling of Lipoglycans with Quantum Dots. Biochem. Biophys. Res. Commun. 2009, 380, 1-4.

76. Yamashita, T.; Kawashima, S.; Ohashi, Y.; Ozaki, M.; Ueyama, T.; Ishida, T.; Inoue, N.; Hirata, K.; Akita, H.; Yokoyama, M. Resistance to Endotoxin Shock in Transgenic Mice Overexpressing Endothelial Nitric Oxide Synthase. Circulation 2000, 101, 931-937.

77. Han, S. H.; Farshchi-Heydari, S.; Hall, D. J. Analytical Method for the Fast Time-Domain Reconstruction of Fluorescent Inclusions in Vitro and in Vivo. Biophys. J. 2010, 98, 350357.

78. Schimpf, M. E.; Caldwell, K.; Giddings, J. C. Field Flow Fractionation Handbook; Wiley-Interscience: New York, 2000; $p$ xviii, $592 \mathrm{p}$.

79. Yu, W. W.; Qu, L. H.; Guo, W. Z.; Peng, X. G. Experimental Determination of the Extinction Coefficient of CdTe, CdSe, and CdS Nanocrystals. Chem. Mater. 2003, 15, 2854-2860. 